\title{
RÉGIMEN ELECTORAL DE GÉNERO Y REPRESENTACIÓN POLÍTICA DE LAS MUjeres a NIVEl SUbNaCiONAl EN MÉXICO
}

\author{
Electoral Gender Regime and Subnational Women's Representation in \\ Mexico
}

\section{FLAVIA FREIDENBERG}

Instituto de Investigaciones Jurídicas, UNAM, México y Red de Politólogas

\author{
SEBASTIÁN GARRIDO DE SIERRA
}

Centro de Investigación y Docencia Económica, México

\begin{abstract}
RESUMEN
En las últimas décadas, México ha introducido reglas electorales cada vez más fuertes en materia de régimen electoral de género al mismo tiempo que la representación descriptiva de las mujeres se ha ido incrementando. Este artículo tiene como objetivo analizar empíricamente la capacidad explicativa de la fortaleza del régimen electoral de género sobre la representación descriptiva de las mujeres en los congresos locales de las 32 entidades federativas, ampliando el análisis longitudinal a partir de la inclusión de los datos de la integración de la mayoría de las legislaturas estatales entre 1987 y 2019. Esto con la intención de identificar a) si el régimen electoral de género de cada entidad federativa se ha fortalecido (comparación diacrónica); b) si existe una relación positiva y sustantiva entre la fortaleza del régimen electoral de género (comparación sincrónica) y la proporción de legisladoras en cada Congreso estatal. Los resultados de la investigación sugieren que, efectivamente, mientras más fuerte sea el régimen electoral de género mayor será la proporción predicha de mujeres electas por los principios de mayoría relativa y representación proporcional, aún después de controlar por otros factores políticos y socioeconómicos. Los resultados también ilustran que el efecto del índice régimen electoral de género no es homogéneo entre entidades subnacionales.
\end{abstract}

Palabras clave: representación descriptiva, mujeres políticas, brecha de género, instituciones legislativas subnacionales, México.

\begin{abstract}
In recent decades, Mexico has introduced increasingly strict electoral rules regarding the gender electoral regime, while the descriptive representation of women has been increasing. This article analyzes empirically the relationship between the strength of the gender electoral regime and the descriptive representation of women in local congresses of the 32 states, expanding the longitudinal analysis based on the data of most local legislatures between 1987 and 2019. It aims to identify whether the gender electoral regime of each state has been strengthened (diachronic comparison) and if there is a positive relationship between the strength of the gender electoral regime (synchronous comparison) and the proportion of female legislators in each local congress. The results of this research suggest that the stronger the gender electoral regime, the greater the predicted proportion of women elected by the principles of relative majority and proportional representation, even after controlling for other political and socioeconomic factors. The results also illustrate that the effect of the gender electoral regime index is not homogeneous among sub-national entities.
\end{abstract}

Keywords: descriptive representation, political women, gender gap, subnational legislative institutions, Mexico. 


\section{INTRODUCCIÓN ${ }^{1}$}

La ausencia histórica de las mujeres en la elaboración e implementación de políticas públicas y en las instituciones ha evidenciado fallas en el funcionamiento de los sistemas políticos (Bareiro y Soto 2015; Schwindt-Bayer 2018). El hecho de que la mitad de la población no participe en las decisiones públicas ha limitado los procesos de democratización a nivel nacional y subnacional pero no ha impedido que los sistemas políticos funcionaran en sus tareas como seleccionar élites, tomar decisiones, gobernar o negociar entre las fuerzas políticas. Desde hace décadas, la literatura comparada y la experiencia política han evidenciado que las mujeres han sido sistemáticamente excluidas de los espacios de poder y de la representación política (Matland 1998; Krook 2010; Bareiro y Soto 2015) y que ese tipo de ausencias limita las oportunidades de democratización.

Esta dramática realidad ha llevado a que el movimiento amplio de mujeres, colectivas feministas, autoridades electorales y/o agencias de la cooperación internacional impulsaran reformas electorales que contribuyeran a cambiar la situación de desigualdad estructural que enfrentan las mujeres cuando quieren hacer política (Matland 1998; Dahlerup y Freidenvall 2005). América Latina ha sido un contexto ejemplar para evaluar el modo en que las medidas afirmativas y la regla de paridad de género han contribuido a romper las resistencias que mantenían a las mujeres fuera de los núcleos de poder (Franceschet et al. 2012; Piscopo 2015; Archenti y Tula 2017; Caminotti y Freidenberg 2018; Schwindt-Bayer 2018). Tras décadas de innovación política, las medidas resultaron muy efectivas, rebasando el umbral del 30 por ciento de la representación legislativa descriptiva femenina a nivel nacional (CEPAL 2020) y transformando el modo en que se accede a las instituciones democráticas en los países de la región.

Dado que todos los países cuentan con algún tipo de sistema político multinivel (Schakel 2013), la subrepresentación política de las mujeres no es sólo un problema nacional, sino que, por el contrario, es precisamente en el nivel subnacional donde se encuentran los principales obstáculos para hacer política en igualdad de condiciones (Massolo 2007; Tello Sánchez 2009; PNUD 2013; ONU 2018). Esta no es una cuestión menor. Si bien se ha avanzado de manera sustantiva en la representación de las legisladoras a nivel nacional, los esfuerzos a nivel subnacional han sido insuficientes y dan cuenta de la necesidad de mirar hacia lo local y lo estatal. Los datos en ese sentido son claros. El promedio de mujeres en los cargos ejecutivos locales alcanza actualmente sólo el 15,5 por

Esta investigación forma parte del Observatorio de Reformas Políticas de América Latina (\#ObservatorioREFPOL), del Instituto de Investigaciones Jurídicas de la Universidad Nacional Autónoma de México y la Organización de los Estados Americanos. La misma también se inscribe en los productos desarrollados para el proyecto "De la representación descriptiva a la sustantiva: la evaluación de la implementación de la paridad de género en los Congresos mexicanos". Fondo Sectorial de Investigación y Desarrollo del INMUJERES-CONACYT [Código Proyecto 309295]. Los autores agradecen el apoyo en la elaboración de las bases de datos a Ricardo Basurto Tapia y Mauricio Morales Betancourt y los comentarios de Karolina M. Gilas y cuatro dictaminadores externos a la revista. 
ciento mientras que a nivel legislativo local asciende a 25 puntos porcentuales en los más de 15.000 municipios de la región (CEPAL 2020).

A pesar de que "toda la política es local" (O’Neill y Hymel 1994), la mayor parte de la academia, de las dirigencias políticas y de los tomadores de decisiones han reproducido cierto "sesgo nacional" (Rokkan 1970) al abordar lo que ocurre con la participación política de las mujeres. Si bien en el nivel subnacional se han impulsado innovaciones normativas que han ampliado las exigencias legales hacia los partidos, incluso antes de que ocurriera en el nivel nacional; la ausencia de datos y la dificultad para hacer análisis comparados robustos han limitado la investigación sobre el tema. A diferencia de ello, estamos convencidos de que esas dinámicas resultan claves para comprender el origen de la democratización de los sistemas políticos (Harbers et al. 2019: 2; Giraudy et al. 2019: 14), la expansión de los derechos y el modo en que unas unidades influyen sobre otras como parte de un proceso de difusión de reglas y derechos en el territorio (Freidenberg y Suárez Cao 2014). Las entidades subnacionales pueden ser agentes de acción o de presión -cada una a su ritmo y modo- para que se cambie el marco normativo nacional o el de otras unidades estatales ampliando los derechos políticos-electorales de las mujeres, aunque también pueden ser un espacio de retroceso de derechos, dado que las élites políticas pueden resistirse a las transformaciones generadas desde lo nacional, gracias a sus atribuciones y competencias para ejercer su autonomía.

Si bien en los últimos años se ha generado una incipiente -pero vibrante- literatura que ha analizado la experiencia de las mujeres políticas a nivel subnacional en América Latina, aún existen vacíos importantes respecto a los factores que explican los niveles de representación legislativa de manera comparada entre unidades subnacionales. México es un excelente laboratorio para contribuir en esa discusión, al ser un país federal que cuenta con 32 entidades, que históricamente han tenido la posibilidad de ejercer federalismo electoral, es decir, la oportunidad de diseñar, innovar y emplear reglas propias en material electoral (Cornelius et al. 1999; Caminotti y Freidenberg 2016). Esto resulta interesante, además, porque tras la reforma constitucional de 2014 se ha caminado hacia la transformación de ese federalismo hacia una mayor nacionalización del sistema electoral, lo que supone la armonización de las reglas electorales en el territorio, modificando el modo en que históricamente se han dado las relaciones entre lo nacional y lo estatal y evidenciando las diferencias sustantivas de la extensión de la ciudadanía política dentro de las unidades estatales. Esa idea potente desarrollada por O'Donnell (1999), Cornelius et al. (1999) o Snyder (2001) respecto a las diferencias de democratización en el territorio se evidencian de manera clara cuando se observa la representación política de las mujeres y, precisamente, este ha sido uno de los argumentos usados para la nacionalización del sistema electoral mexicano.

¿Por qué unas legislaturas estatales cuentan con más mujeres representantes que otras? Esta pregunta de investigación es el eje de este estudio exploratorio que evalúa las razones político-institucionales y socioeconómicas que inciden 
en que unas legislaturas de las entidades federativas mexicanas hayan tenido en un determinado momento un porcentaje mayor de mujeres electas que otras en el período 1987-2019. A diferencia de la literatura que ha estudiado aspectos de este fenómeno en elecciones a nivel nacional, de manera diacrónica en una u otra entidad o en períodos más estrechos de tiempo, esta investigación comparada explora los factores que explican la representación descriptiva de las mujeres a nivel de los legislativos subnacionales de las 32 entidades federativas en un período de al menos treinta años, a partir de la construcción de una base de datos original desarrollada de manera específica para este estudio.

Con esta investigación se pretende aportar conocimiento sobre la variación territorial de la representación política de las mujeres. El objetivo es, primero, describir los niveles de representación política de las mujeres en las legislaturas subnacionales y, segundo, explicar las razones que llevan a que unas legislaturas tengan más representación descriptiva de las mujeres que otras. Este estudio evalúa el peso de variables institucionales (como el nivel de fortaleza del régimen electoral de género en el registro de candidaturas, en relación a diferentes principios de elección y tipos de distritos del sistema electoral -representación proporcional y mayoría relativa) y variables socioeconómicas (nivel de desarrollo económico, modernización y nivel educativo), controladas por la trayectoria del régimen electoral de género y la alternancia político-partidista en cada entidad federativa, sobre la representación descriptiva de las mujeres a nivel legislativo subnacional.

El argumento principal sostiene que cuanto más fuerte resulte el régimen electoral de género para el registro de candidaturas, mayor será la representación política de las mujeres en las instituciones legislativas subnacionales, sin importar el tipo de sistema electoral. Este argumento es respaldado por los resultados de diversos modelos logísticos binomiales de efectos mixtos que indican que, después de controlar por diferentes variables, un incremento en el "Índice de Fortaleza del Régimen Electoral de Género" de 0 a 5 (es decir, del valor mínimo al máximo) está asociado con un aumento de $85.6 \%$ en la proporción predicha de mujeres electas por el principio de mayoría relativa y de $35.2 \%$ por el de representación proporcional. Los resultados del modelo también sugieren que el efecto del índice no es homogéneo entre entidades y de la necesidad de explorar otras variables subnacionales en próximas investigaciones como la trayectoria política de las mujeres, el nivel de asociacionismo y la capacidad de articular redes de apoyo o de movilización jurídica.

La estructura de este texto tiene seis partes. Primero, se discute teóricamente sobre diversas hipótesis que pueden explicar los diferentes niveles de representación de las mujeres. Segundo, se describe la evolución del régimen electoral de género multinivel en México -una de las variables independientes de esta investigación-. Tercero, se hacen explícitas las decisiones metodológicas tomadas para medir las diversas variables independientes y la dependiente que se exploran en la investigación. Cuarto, se analizan los datos y se evalúan las diversas hipótesis para establecer en qué medida los factores institucionales 
y socioeconómicos explican las variaciones en la representación política de las mujeres. Quinto, se presentan los modelos estadísticos que se emplean para el análisis de los datos. Finalmente, se reflexiona en torno a una serie de conclusiones respecto a los hallazgos realizados y se delinea una agenda de investigación futura en materia de representación política de las mujeres a nivel subnacional.

\section{DISCUSIÓN TEÓRICA}

Diversas hipótesis se han empleado en la literatura comparada para explicar el cambio en los niveles de representación de las mujeres, ya sea a nivel descriptivo, simbólico o sustantivo (Pitkin 1985). Variables político-institucionales, de movilización social, socioeconómicas o culturales han sido investigadas respecto a su incidencia sobre la representación de las mujeres en las instituciones legislativas (Krook 2010; Jones et al. 2012; Piscopo 2015; Schwindt-Bayer 2018; Freidenberg 2020). Si bien la mayor parte de esas exploraciones fueron realizadas en relación con la representación de las legislaturas nacionales, de manera reciente se ha evaluado el peso de diversas variables que originalmente habían sido pensadas a nivel nacional para explicar dinámicas del nivel subnacional (estatal y local), dando cuenta de su capacidad de superar el problema del "estiramiento teórico" (Giraudy et al. 2019) y de los retos que el estudio de la representación política supone en sistemas políticos multinivel. ${ }^{2}$

Las razones que explican las diferencias existentes en los porcentajes de candidaturas ganadoras en las diversas legislaturas de una unidad subnacional (estado/provincia/departamento) en el tiempo (Flores Ivich y Freidenberg 2017) como también entre las distintas unidades de un mismo sistema político (Caminotti y Freidenberg 2016; Alles 2018; Schmidt 2020) pueden agruparse para esta investigación en dos grupos: explicaciones político-institucionales y socioeconómicas, aún cuando la literatura comparada también ha explorado de manera limitada por las dificultades de acceso a datos otro tipo de explicaciones como las actitudinales y culturales o de movilización social y jurídica.

\section{Variables político-institucionales: el nivel de fortaleza y la antigüedad del régimen electoral de género}

La mayor parte de la literatura académica explica el incremento del número de legisladoras por la implementación de medidas de acción afirmativa y/o de principios constitucionales como el de la paridad de género en el registro de

En futuras investigaciones sería interesante pensar en un índice agregado multinivel de representación política descriptiva de las mujeres con el que puedan registrarse las diferencias entre niveles institucionales (nacional, subnacional, local) y por tipo de elección (ejecutiva, legislativa), el cual permita comparar casos nacionales entre sí de manera multinivel para poder evaluar los avances (o retrocesos) realizados. 
las candidaturas a cargos de representación popular (Krook 2010; Franceschet et al. 2012; Jones et al. 2012; Piscopo 2015; Freidenberg 2020). Se entiende como cuotas de género las medidas que "(a) buscan aumentar el número de mujeres candidatas a los cargos políticos y (b) están articuladas explícitamente de alguna manera" en las leyes o normas que establecen el modo en que se registran las candidaturas a cargos de representación popular (Caminotti 2016). La paridad de género, a diferencia de las cuotas, hace referencia al principio permanente que busca integrar la diferencia sexual a la democracia representativa, lo que significa un paso hacia la democracia paritaria (Bareiro y Soto 2015).

Las reformas vinculadas el "régimen electoral de género", es decir, las reglas que establecen el modo en que se registran las candidaturas a los cargos de representación popular (Freidenberg 2020) bajo el supuesto de que exigir a los partidos ubicar mujeres en las candidaturas legislativas mejoraría su representación política y de que se daría un efecto cascada hacia los otros cargos de elección. Este supuesto dio resultado -al menos en parte- porque las más de 40 reformas al régimen electoral de género nacional en 19 países de América Latina (Freidenberg 2020) implicó un incremento sustantivo de la presencia de mujeres en los legislativos nacionales (CEPAL 2020).

Esta misma hipótesis se ha trasladado a la evaluación de la representación política descriptiva en las entidades federativas mexicanas (Zetterberg 2007; Peña Molina 2014; Caminotti y Freidenberg 2016; Vidal Correa 2016; Flores Ivich y Freidenberg 2017; entre otros), aunque las mismas han sido exploradas comparando pocas unidades subnacionales, algunos diseños electorales determinados en un momento de tiempo específico y no se había podido realizar una evaluación de larga data con un número amplio de elecciones, en diferentes tipos de distritos y múltiples regímenes electorales de género diferenciados. De cualquier modo, las investigaciones realizadas han contribuido a discutir la validez de lo que inicialmente se había planteado a nivel nacional.

La ausencia (o la debilidad) de esas reglas electorales, la presencia de válvulas de escape, es decir, reglas que permiten no cumplir con lo que exige el régimen electoral de género (como el uso de procedimientos democráticos para seleccionar candidaturas -como ocurría en México- o poder argumentar que no hay mujeres para cubrir los puestos -como sucede hoy en Panamá-), y/o el cuestionamiento que las reglas informales (como la simulación partidista) hacen sobre las reglas formales, funcionan como barreras difíciles de romper para las mujeres que quieren participar en política. Diversas investigaciones han hecho hincapié en que el nivel de representación política varía en función de los componentes del régimen electoral de género, como es el porcentaje de exigencia (Htun y Jones 2002; Caminotti y Freidenberg 2016; Schwindt-Bayer 2018); el mandato de posición, que exige ubicar a las candidatas en lugares expectables y no puramente simbólicos (Baldez 2004); la presencia de sanciones fuertes por el incumplimiento de la exigencia; y la ausencia de válvulas de escape, dado que este tipo de medidas permiten la manipulación estratégica de los actores partidistas (Caminotti y Freidenberg 2016; Freidenberg 2020). 
La eficiencia del régimen electoral de género mejora sustantivamente al contar con un sistema electoral específico (Reynolds 1999; Htun y Jones 2002; Jones et al. 2012; Caminotti y Freidenberg 2016). Especialmente, los sistemas de representación proporcional con listas cerradas y bloqueadas, en distritos grandes o medianos (Htun y Jones 2002; Jones et al. 2012; Alles 2018) tienden a ser más amigables con la representación de las mujeres que los distritos uninominales de mayoría relativa (Langston y Aparicio 2014). Precisamente, un elemento del régimen electoral de género que tensiona con el tipo de sistema electoral es el mandato de posición. Estos funcionan a favor de las mujeres cuando las listas son cerradas y bloqueadas, ya que pierden valor en sistemas de lista abierta o de voto preferencial. La experiencia comparada evidencia que, en los países donde se ha aprobado cuota o paridad de género y cuentan con voto preferencial, la representación de las mujeres es mucho menor (Ecuador, República Dominicana y Honduras) o, como ha evidenciado Schmidt (2020) el tipo de lista cerrada resulta más beneficioso para las candidatas de las provincias peruanas que para las que compiten en Lima, cuando ellas tienen prestigio personal previo, donde el voto preferencial no necesariamente parecería afectar su elección.

La hipótesis más consensuada sostiene que el nivel de fortaleza del régimen electoral de género mejora sustantivamente la representación de las mujeres (Matland 1998; Dahlerup y Freidenvall 2005; Krook 2010; Schwindt-Bayer 2018; Caminotti y Freidenberg 2018; Freidenberg 2020). Un régimen electoral de género es fuerte cuando establece un porcentaje alto de exigencia (umbral), aplicada a la fórmula completa (candidaturas titulares y suplentes), con mandato de posición explícito, evitando que ubiquen a las mujeres en candidaturas donde el partido suele perder las elecciones; enforcements alto (monitoreo, control y sanciones fuertes por no cumplir la cuota) y ausencia de válvulas de escape, lo que evite que los partidos puedan esquivar cumplir con lo que les exige el régimen electoral de género. ${ }^{3}$ De ese modo, para esta investigación se expresa que

Hipótesis 1: Cuanto más fuerte sea el régimen electoral de género en el registro de candidaturas, mayor será la representación descriptiva de las mujeres en las legislaturas de las entidades federativas.

Otra expectativa razonable respecto a la efectividad de las medidas de acción afirmativa (la cuota) y/o la paridad es que se necesita un proceso de aprendizaje por parte de la ciudadanía y las élites político-partidistas para acostumbrarse a la presencia de las mujeres en la esfera pública (Caminotti y Freidenberg 2016), ya que esto incrementa la visibilidad de la agenda de género e internaliza el hecho de tener mujeres en los cargos públicos como parte de una práctica cotidiana que afecta la representación simbólica. De esa manera, se podría es-

Por "candidaturas simbólicas" se entienden los últimos lugares de las listas plurinominales, así como las candidaturas en distritos uninominales, que no son seguros para el partido. Inversamente, por candidaturas efectivas se entiende a aquellas que tienen probabilidades de ganar (Caminotti 2016). 
perar una relación positiva entre el tiempo de vigencia desde la aprobación de la cuota y/o paridad (su edad) y la representación de las mujeres en las legislaturas. En ese sentido, se sostiene que

Hipótesis 2: Cuanto mayor sea el tiempo de vigencia de la medida de acción afirmativa (cuota) y/o de la paridad, mayor será el aprendizaje respecto a la participación de las mujeres en los cargos y mayor será la representación descriptiva de las mujeres en las legislaturas de las entidades federativas.

\section{Variables socioeconómicas: el nivel de desarrollo económico subnacional, modernización y nivel educativo}

El contexto socioeconómico de la entidad federativa puede incidir sobre la representación de las mujeres en su estado y sobre el funcionamiento de las medidas de acción afirmativa que intervienen en el registro de candidaturas y los recursos personales que tienen las mujeres que quieren competir (Matland 1998; Rosen 2012). Diversas investigaciones (Inglehart y Norris 2003) han evidenciado cómo la transformación de las sociedades orientadas a un mayor desarrollo económico, un mayor nivel educativo y acceso a recursos impactan la participación política. En ese sentido, la cada vez mayor autonomía financiera, la superación de la desigualdad en el acceso al mercado de trabajo, la cada vez mayor disponibilidad de tiempo para conciliar la vida personal con la profesional y el acceso a recursos personales afecta sus niveles de participación política y, de manera específica, sus posibilidades de éxito electoral.

A diferencia de las variables político-institucionales, las aproximaciones socioeconómicas casi no han sido exploradas en América Latina. De ahí la necesidad de analizar en qué medida este conjunto de ideas relacionadas con el desarrollo socioeconómico tiene relación con la representación de las mujeres. La literatura ha señalado su interacción sobre la brecha de género en el mercado de trabajo (Gilas 2014: 54); sobre la autonomía económica de las mujeres y la disparidad en los logros educativos; sobre las tareas familiares basadas en roles de género y el escaso tiempo que los hombres dedican a la vida doméstica (CIM 2013: 20) y sobre las preferencias y valores de la ciudadanía exigiendo mayor participación de las mujeres en la política (Inglehart y Norris 2003).

De ahí que se sostenga que el desarrollo económico, medido por el nivel de producto interno bruto per cápita, genera mayores condiciones sistémicas para la participación y la representación política de las mujeres. Si bien recientes investigaciones han explorado estas explicaciones en determinados contextos subnacionales (Caminotti y Freidenberg 2016; Schmidt 2020), no encontramos por el momento investigaciones que permitan dar cuenta de esa hipótesis en las entidades mexicanas para un período de tiempo extenso. En este sentido, siguiendo esta línea de explicación, para esta investigación se sostiene que 
Hipótesis 3: Cuanto mayor sea el producto interno bruto per cápita de una entidad federativa, mayor será la representación descriptiva de las mujeres en la legislatura de esa entidad.

Hipótesis 4: Cuanto mayor sea el porcentaje de población que vive en comunidades urbanas en una entidad federativa, mayor será la representación descriptiva de las mujeres en las legislaturas de esa entidad.

Hipótesis 5: Cuanto mayor sea el porcentaje de población con al menos un año completo de educación superior, mayor será la representación descriptiva de las mujeres en las legislaturas de esa entidad.

\section{LA EVOLUCIÓN DEL RÉGIMEN ELECTORAL DE GÉNERO EN LAS ENTIDADES FEDERATIVAS Y EN EL NIVEL FEDERAL EN MÉXICO}

México es un sistema político federal multinivel, donde los estados cuentan con instituciones, sistemas electorales y sistemas de partidos diferenciados. En ese escenario inicial se dio el proceso de construcción del régimen electoral de género a nivel federal que -en la actualidad- es el más fuerte de América Latina (Freidenberg 2020) y ese proceso ha tenido efectos sobre la regulación subnacional, ya sea a través de las normas así como también por el peso de los actores institucionales nacionales (como el Instituto Nacional Electoral -INE- o el Tribunal Electoral del Poder Judicial de la Federación -TEPJF-) que han presionado sobre las autoridades electorales subnacionales para la armonización normativa en materia del registro de las candidaturas a los cargos de representación popular (Organismos Políticos Electorales Locales -OPLES-).

Si bien el resultado actual es un proceso muy exitoso, el camino ha sido sinuoso y ha tenido avances, pero también retrocesos, debido a que los y las legisladoras han ido dejando vacíos y lagunas que permitieron simulaciones y resistencias por parte de los partidos (Palma y Chimal 2012; Gilas 2014; Hevia Rocha 2020), agravándose esas malas prácticas a nivel estatal y local. A cada cambio institucional de las reglas formales nacionales o subnacionales, las élites han creado una simulación o práctica informal para no cumplir con lo que señala la norma (Piscopo 2016). Los partidos han hecho un doble juego que va entre la promoción de los derechos políticos-electorales de las mujeres y las resistencias a que ellas accedan a los cargos en igualdad de condiciones que los hombres. ${ }^{4}$ En este sentido, la historia política mexicana en materia de participación polí-

Por ejemplo, los partidos ubicaban a las mujeres en las candidaturas 'simbólicas', como suplentes, en los últimos lugares de las listas de representación proporcional, lo que permitía hacer un cumplimiento formal de la cuota, aunque no era efectivo en cuanto a sus efectos sobre la representación de las mujeres. También las enviaban a distritos donde los partidos siempre perdían e incluso sin recursos ni apoyo real del aparato partidista. 
tica de las mujeres se ha caracterizado por la ampliación de derechos y la articulación de resistencias (Reynoso y D’Angelo 2006; Freidenberg y Gilas 2020).

Las primeras legislaciones federales de 1993 y 1996 establecieron únicamente recomendaciones para que los partidos políticos incrementaran el número de mujeres candidatas a los cargos legislativos. ${ }^{5}$ Las sucesivas modificaciones y adiciones al Código Federal de Instituciones y Procedimientos Electorales (COFIPE) plantearon a partir de 2002 cuotas obligatorias de 30\%, luego en 2008 del $40 \%$, donde además se estableció que las listas se integraran de manera alternada y se mantuvieron sanciones por incumplimiento hasta plantear la obligatoriedad de la paridad (2013/2014). ${ }^{7}$ En los estados, las reformas electorales se desarrollaron en fases. En la década de 1990, la recomendación federal para la integración de mujeres en las candidaturas hizo que algunos estados incorporaran medidas semejantes en su legislación. En estos años, incluso un estado (Chihuahua en 1994) aprobó una cuota del 30\% cuando no era común que esto se plasmara en la legislación subnacional y mucho menos que una entidad aprobara una ley que desafiaba lo que establecía la normativa nacional.

En una segunda fase, diversos estados adoptaron algún tipo de cuota, ya sea de 30\% (Estado de México, Distrito Federal, Michoacán, Oaxaca, Guerrero, Jalisco, Colima, Durango) o menor (Puebla, Sinaloa o Sonora). Esto ocurrió antes de que la reforma federal de 2002 obligara a los partidos a respetar las cuotas, lo que da cuenta del nivel de autonomía subnacional y de cómo desde los estados se pueden ampliar derechos antes que lo haga la autoridad nacional. En una tercera fase, un número importante de estados incorporó cuotas de género a sus Códigos obligados por la reforma federal de 2002. Así, seis estados introdujeron un piso de 30\% siendo para muchos un verdadero techo de representación (como Aguascalientes, Campeche, Quintana Roo, Tamaulipas, Yucatán, Zacatecas). Finalmente, en una cuarta fase, entre 2010 y 2011, once estados realizaron reformas orientadas al "horizonte paritario", incorporando una cuota de $40 \%$ (Colima, Distrito Federal, Estado de México, Aguascalientes, Baja California, Coahuila, Querétaro, Sinaloa, Tabasco, Tamaulipas y Zacatecas).

\footnotetext{
La legislación de 1993 sugería a los partidos promover una mayor participación de las mujeres (Fracción 3 del artículo 175 del COFIPE). En 1996, la legislación recomendó que no se presentaran candidaturas con más de $70 \%$ de personas del mismo género.

6 La obligación del uso de las cuotas de género a nivel federal de 2002 aprobó la exigencia del 30 por ciento en los distritos plurinominales, con mandatos de posición en las listas de representación proporcional (uno de tres) y también la exigencia de otro 30 por ciento en distritos uninominales, salvo que las candidaturas fueran seleccionadas a través de procesos democráticos, lo que suponía una válvula de escape para el no cumplimiento de la norma (Baldez 2004).

7 Tras el escándalo denominado como de las "juanitas" de 2009 (en el que ocho mujeres electas por el PRI, el PVEM, el PRD y el PT solicitaron licencia y la consiguieron para ceder sus escaños en la Cámara de Diputados Federal a sus suplentes hombres) y la elección de 2011-2012, se presentó una demanda ante el TEPJF y éste sentenció que la fórmula completa (propietario y suplente) debía ser integrada por mujeres y no habría excepciones en función del método de selección de candidatos. En 2011 el Instituto Federal Electoral (IFE) acordó que los partidos deberían presentar al menos 120 y 26 candidaturas federales para Diputados y Senadores de un mismo sexo para cumplir con las disposiciones del COFIPE (CG413/2011) (ONU et al. 2012).
} 
Algunos estados se adelantaron nuevamente a las leyes federales y aprobaron la paridad antes de que se diera la reforma federal de 2014. Trece entidades incorporaron la exigencia de paridad, de los cuales sólo dos no contemplaban en ese período excepciones por mecanismo de selección de candidaturas (Puebla y Baja California Sur) y había un estado que carecía de mecanismo de acción afirmativa para la elección de legisladores a través de la representación proporcional (Nuevo León). La reforma de 2014 introdujo la paridad de género en las candidaturas a los cargos de elección popular a nivel constitucional, tanto en el nivel federal como estatal, aunque el proceso de armonización de las leyes federales y locales necesitó del TEPJF para conducir a varios estados en la senda de la paridad, dado que las élites subnacionales manifestaron nuevamente fuertes resistencias para aceptar lo que establecía la Constitución (Freidenberg y Gilas 2020). ${ }^{8}$ Si bien el texto constitucional era claro respecto a la introducción de la paridad, tanto en las candidaturas postuladas por el principio de mayoría relativa como por el de representación proporcional (paridad vertical), el TEPJF tuvo que resolver un cuestionamiento partidista que ponía dudas sobre el alcance de la norma para los cargos subnacionales en 2015 (Alanis Figueroa 2017).

La nueva legislación electoral incorporó la exigencia de la postulación de fórmulas completas de un sólo género, conservó la regla de la alternancia de género en listas cerradas y bloqueadas para el principio de representación proporcional e introdujo de manera innovadora la prohibición de que las candidaturas de un mismo género estuvieran asignadas a lo que se ha considerado como distritos perdedores (Gilas y Christiansson 2018). Estos cambios se trasladaron a las entidades federativas a partir del Acuerdo del Consejo General del INE en el que se estableció cómo debían ser las reglas que las entidades debían incorporar en su legislación. ${ }^{9}$ Esto evidencia claramente el cambio de la dinámica multinivel del sistema político, pasando de un sistema de federalismo electoral a otro de nacionalización electoral, donde las entidades federativas fueron perdiendo su capacidad de autonomía e iniciativa frente a las directrices del INE. ${ }^{10}$

$8 \quad$ El papel de la justicia electoral en el caso mexicano es clave para comprender los avances en la protección de los derechos. El TEPJF generó algunos de los criterios relevantes como el aval para la sustitución de candidaturas en las listas que no habían cumplido con la medida afirmativa (SUP-JDC-155/2004), la obligación de las autoridades electorales de verificar el cumplimiento de las cuotas (SUP-JRC-336/2004, SUP-JRC-170/2006) o la aplicación efectiva de las reglas de alternancia en las listas (SUP-JDC-1130/2006) (Freidenberg y Gilas 2020).

$9 \quad$ Acuerdo del Consejo General del Instituto Nacional Electoral por el que, en ejercicio de la facultad de atracción, se emiten criterios generales a efecto de garantizar el cumplimiento al principio de paridad de género en la postulación de candidaturas para todos los cargos de elección popular a nivel local, del 15 de febrero de 2017 (CG63/2016).

10 Respondiendo a las indicaciones del INE, los OPLES aprobaron de enero de 2015 a diciembre de 2018 los nuevos lineamientos (Morelos, 16 de enero de 2015; Tabasco, 30 de noviembre de 2016; Chiapas, 14 de diciembre de 2016; Nayarit, 27 de marzo de 2017; San Luis Potosí, 19 de julio de 2017; Querétaro, 30 de agosto de 2017; Guanajuato, 31 de agosto de 2017; Campeche, 21 de septiembre de 2017; Michoacán, 26 de septiembre de 2017; Ciudad de México, 28 de septiembre de 2017; Tamaulipas, 12 de octubre de 2017; Colima, 13 de octubre de 2017; Yucatán, 20 de octubre de 2017; Jalisco, 3 de noviembre de 2017; Aguascalientes, 9 de noviembre de 2017; Estado de México 9 de noviembre de 2017; Guerrero, 16 de noviembre de 2017; Nuevo León, 22 de noviembre de 2017; Zacatecas, 27 de noviembre de 2017; Tlaxcala, 13 de diciembre de 2017; Durango, 14 de diciembre de 2017; Oaxaca, 18 de diciembre de 2017; Baja California Sur, 21 de diciembre 
La indicación de este órgano nacional a los OPLES fue que aprobaran sus Lineamientos de Paridad en donde se establecía el modo en que debían interpretarse el mandato de posición, el principio de competitividad y la regla de los distritos perdedores, con el objetivo de que los partidos pudieran contar reglas claras sobre cómo debían integrar sus candidaturas. Estos lineamientos evidencian formas concretas de enfrentar las prácticas de simulación y las resistencias que impulsaron los partidos para no cumplir con lo que exigía la ley o para simular que las cumplían (Hevia Rocha 2020). Además, en noviembre de 2017, el INE estableció nuevos criterios e incluso nuevas medidas de acción afirmativas que reforzaban el alcance del principio de paridad constitucional tanto a nivel federal como subnacional. ${ }^{11}$

\section{DECISIONES METODOLÓGICAS}

El objetivo de esta investigación es identificar las razones que inciden en el nivel de representación descriptiva de las mujeres en las legislaturas de las entidades federativas mexicanas en el período 1987-2019. Para ello se emplea el método comparado subnacional (Snyder 2001; Harbers et al. 2019), junto a técnicas cuantitativas, para identificar las propiedades, comparar las semejanzas y diferencias y establecer las variaciones en las unidades subnacionales (legislaturas). El estudio se nutre del neoinstitucionalismo feminista a partir del cual se identifican las desigualdades de género que afectan la competencia política y supone enfocar el análisis en el modo en que las normas construyen, reproducen, afectan y mantienen dinámicas de poder generizadas (MacKay et al. 2010).

Si bien diversas dimensiones de este problema se han analizado en trabajos previos (Caminotti y Freidenberg 2016; Flores Ivich y Freidenberg 2017), esta investigación actualiza y extiende estos estudios de tres maneras. Primero, ampliando el período temporal que cubre la base de datos para incluir la integración por género de entre seis (Puebla) y 11 (ocho entidades) legislaturas locales en cada una de las 32 entidades federativas de México ${ }^{12}$ durante el período 1987-2019 (ver Figura 1). ${ }^{13}$ La variación en el número de legislaturas analizadas

de 2017; Hidalgo, 21 de diciembre de 2017; Puebla, 22 de diciembre de 2017; Coahuila, 24 de diciembre de 2017; Sonora, 7 de enero de 2018; Sinaloa, 15 de enero de 2018; Veracruz, 28 de febrero de 2018; Chihuahua, 3 de marzo de 2018; Quintana Roo, 15 de marzo de 2018; Baja California, 24 de diciembre de 2018).

11 Las nuevas medidas exigieron la postulación de mujeres en los encabezados de las listas de candidaturas por el principio de representación proporcional de la Cámara de Diputados federal y, en el caso del Senado, también la lista de candidaturas por el principio de mayoría relativa. También se obliga a que en las dos fórmulas presentadas por el principio de mayoría relativa para cada entidad se presenten personas de género distinto y que la mitad de las listas de candidaturas por el principio mayoría relativa por entidad deberán estar encabezadas por cada género (Freidenberg y Gilas 2020).

12 En total se incluyen en el análisis a las legisladoras electas por el principio de mayoría relativa en 289 legislaturas y las electas por el principio de representación proporcional en 287.

13 El período de tiempo que se empleó para el análisis estuvo condicionado a la disponibilidad de los datos. Dado que son bases de datos originales, creadas para esta investigación, su elaboración dependió de que los organismos electorales estatales respondieran las solicitudes de información; las consultas personales a través de informantes clave dentro de los organismos electorales, así como también las gestiones realizadas a través de la Dirección de Prerrogativas y de la Unidad Técnica de Vinculación del Instituto Nacional Electoral. El período de recolección de datos fue durante cuatro años (en dos fases, de 2016 a 2017 y de 2018-2020) y ha permitido sistematizar y organizar los datos representación política de las mujeres y hombres para los 
para cada estado es producto tanto de la dificultad para obtener los datos en algunas entidades en períodos específicos, así como de las diferencias en la duración de ciertos períodos legislativos. ${ }^{14}$ Segundo, analizando el efecto de las variables explicativas en la proporción de legisladoras de mayoría relativa y representación proporcional por separado. Tercero, utilizando un modelo logístico binomial. Este modelo es adecuado tanto por la naturaleza de la variable dependiente (una proporción con varianza no constante), como la probable correlación en las observaciones de cada entidad y las diferencias recién mencionadas en el número de legislaturas consideradas para cada entidad. ${ }^{15}$

Figura 1. Número de legislaturas estatales incluidas en el análisis

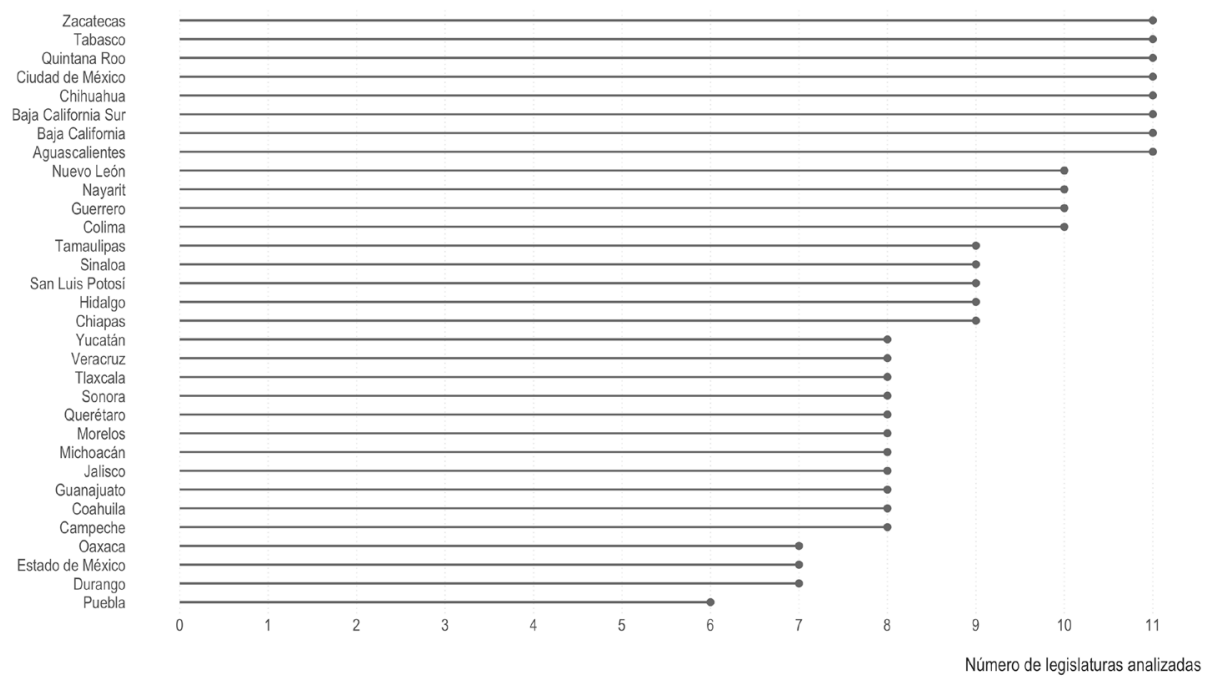

Fuente: Elaboración propia.

La variable dependiente es el nivel de representación descriptiva de las mujeres en las legislaturas de cada entidad federativa. Dado que la principal variable explicativa de este estudio -el "Índice de Fortaleza del Régimen Electoral de Género"- fue diseñada para medir la fortaleza de las normas que regulan el registro de candidaturas para las elecciones legislativas locales de mayoría relativa, por un lado, y de representación proporcional, por el otro, la variable de-

32 estados desde 1987 a 2019. La data de la primera fase de esta investigación se puso a disposición del INE en www.igualdad.ine.mx. No existe otra información disponible sistematizada para un período anterior al cubierto en este estudio.

14 Los períodos legislativos de los congresos locales mexicanos suelen durar tres años. Sin embargo, durante la última década diversas entidades tuvieron períodos de dos y cuatro años para sincronizar su calendario electoral con el de las elecciones federales. La integración de las legislaturas se calcula al momento de inicio del periodo legislativo, con lo cual no se registran los cambios que se han dado a posteriori.

15 Como se explica más adelante, la probable correlación temporal de las observaciones de una misma entidad es modelada rezagando un período la variable dependiente. 
pendiente se operacionaliza de dos maneras. La primera, llamada Proporción legisladoras MR, mide la proporción de legisladoras electas por el principio de mayoría relativa respecto al número total de diputaciones electas por este principio en cada elección y estado. ${ }^{16}$ La segunda versión se llama Proporción legisladoras RP y es construida de la misma manera pero con los datos de las diputaciones electas por el principio de representación proporcional. ${ }^{17}$ Ambas versiones de la variable dependiente fueron construidas a partir de la información de la base de datos original denominada "\#MujeresElectas", realizada originalmente en 2017 para el Instituto Nacional Electoral y actualizada a 2020.

A partir del marco teórico propuesto, las variables independientes exploran preocupaciones respecto al peso de factores político-institucionales y socioeconómicos. Entre los político-institucionales se mide el nivel de fortaleza de las reglas electorales respecto al registro de candidaturas a cargos de representación popular subnacional, a través del "Índice de Fortaleza del Régimen Electoral de Género" (Caminotti y Freidenberg 2016; Freidenberg 2020), que se calcula diferenciando las reglas que rigen los distritos de mayoría relativa de las que rigen en los distritos por representación proporcional. Ésta es una versión actualizada de la construida a partir de la base de datos "\#MujeresEnLasNormas" (Freidenberg y Alva Huitrón 2017), que recoge la legislación electoral y sus cambios de las entidades en el período 1987-2019. Esto supuso identificar 119 cambios de la legislación electoral en las 32 entidades federativas en el período analizado.

El "Índice de Fortaleza del Régimen Electoral de Género" (IFREG) se calculó para cada cambio de la legislación estatal en el período 1987-2019, identificando los valores de este en cinco propiedades que tienen el mismo valor (Tabla 1), a partir del cual se construyen una medida agregada que permite comparar las observaciones de los cambios en las reglas electorales de las entidades federativas. Las dimensiones que integran el IFREG son las siguientes:

1. el tamaño de la medida de acción afirmativa y/o paridad de género (el porcentaje de mujeres que se exige nominar en las candidaturas);

2. el mandato de posición de la cuota y / o de la paridad (la exigencia de ubicar a las mujeres en candidaturas efectivas y no sólo simbólicas);

3. el enforcement o los mecanismos que penalizan el incumplimiento de las cuotas y/o de la paridad (multas, amonestaciones, no oficialización de listas, pérdida del registro del partido, no acceso a financiamiento, entre otros);

4. el alcance de la cuota y/o de la paridad (es decir, si se la aplica solo a las candidaturas propietarias o también a las suplencias, lo que se denomina como "fórmula completa");

16 Como se explica en la siguiente sección, al momento de construir el modelo no se utiliza directamente la proporción de legisladoras electas por cada principio, sino el número de legisladoras electas y el número total de curules del congreso correspondiente.

$17 \quad$ En cada una de las entidades federativas mexicanas se elige el mismo día a la totalidad de las diputaciones de mayoría relativa y de representación proporcional. 
5. las válvulas de escape de las cuotas y/o de la paridad (que consisten en la previsión de situaciones donde se autoriza a no aplicarlas, como, por ejemplo, cuando se realizan elecciones primarias o cuando se permite que los partidos argumenten que no hay mujeres suficientes para cumplir con la exigencia).

Para la construcción del IFREG se utilizan los datos de la totalidad de las leyes de cuota y del principio de paridad de género en las entidades subnacionales en México, con sus reglamentaciones, diferenciándose según los elementos del sistema electoral como el principio de representación (proporcional y mayoritario) y el tipo de distrito (plurinominales y uninominales).$^{18}$ Dado que el sistema electoral es similar para todos los estados, en la presente investigación no se incluye como una variable que pudiera afectar la representación política.

Tabla 1. Índice de Fortaleza del Régimen Electoral de Género: dimensiones, indicadores y medición

\begin{tabular}{|c|c|c|}
\hline Dimensiones e indicadores & Categorización & Medición \\
\hline \multirow{3}{*}{$\begin{array}{l}\text { 1. Tamaño: porcentaje de las } \\
\text { candidaturas que se deben } \\
\text { asignar a mujeres }\end{array}$} & Mínimo (hasta 30 por ciento) & 0 \\
\hline & Intermedio ( 31 por ciento a 49 por ciento) & 0,5 \\
\hline & $\begin{array}{l}\text { Paritario ( } 50 \text { por ciento) (vertical y/o horizontal), } \\
\text { según el tipo de cargo }\end{array}$ & 1 \\
\hline \multirow{3}{*}{$\begin{array}{l}\text { 2. Mandato de posición: reglas } \\
\text { de emplazamiento de las } \\
\text { candidatas }\end{array}$} & Ausente & 0 \\
\hline & $\begin{array}{l}\text { Débil: posibilidad de ubicar mujeres en últimos } \\
\text { lugares y/o en distritos perdedores }\end{array}$ & 0,5 \\
\hline & $\begin{array}{l}\text { Fuerte: requisito de incorporar mujeres en candi- } \\
\text { daturas "efectivas" (principio de competitividad) }\end{array}$ & 1 \\
\hline \multirow{3}{*}{$\begin{array}{l}\text { 3. Enforcement: penalidad por } \\
\text { incumplimiento de la cuota } \\
\text { (y/o paridad) }\end{array}$} & Ausente & 0 \\
\hline & $\begin{array}{l}\text { Débil: mecanismos que penalizan al partido, pero } \\
\text { se les permite competir. }\end{array}$ & 0,5 \\
\hline & $\begin{array}{l}\text { Fuerte: partidos no pueden participar de la elec- } \\
\text { ción si no cumplen }\end{array}$ & 1 \\
\hline \multirow{2}{*}{$\begin{array}{l}\text { 4. Alcance: rango de candida- } \\
\text { turas a las cuales se aplica la } \\
\text { cuota (y/o paridad) }\end{array}$} & Restringido: candidaturas propietarias & 0 \\
\hline & Amplio: fórmula completa & 1 \\
\hline \multirow{2}{*}{$\begin{array}{l}\text { 5. Válvula de escape: la nor- } \\
\text { mativa contempla excepcio- } \\
\text { nes al cumplimiento de la } \\
\text { cuota (y/o paridad) }\end{array}$} & $\begin{array}{l}\text { Presentes: hay situaciones donde es posible no } \\
\text { aplicar la normativa y/o algunas candidaturas } \\
\text { están exentas }\end{array}$ & 0 \\
\hline & Ausente: no hay excepciones. & 1 \\
\hline
\end{tabular}

Fuente: Elaboración de Caminotti y Freidenberg (2016).

18 Todo sistema electoral cuenta en términos teóricos con distintos elementos, entre los que destacan la fórmula electoral, vinculada al principio de representación, el tipo de distrito, la estructura de voto y el umbral electoral. Aún cuando en el caso mexicano el tipo distrito (uninominal vs. plurinominal) coincide con el principio de representación (distrito uninominal con mayoría relativa y distritos plurinominales con representación proporcional); en términos teóricos, no necesariamente son lo mismo ni siempre van juntos. 
Otra variable institucional explicativa tiene que ver con el tiempo de aprendizaje desde que se aprobó la medida de acción afirmativa y/o el principio de paridad de género. Para construir esta variable, que se denomina en este estudio como "Antigüedad norma de género", también se utilizó la base de datos "\#MujeresEnLasNormas". Para medirla se calculó el número de años transcurridos desde la aprobación de la primera ley que incluyó una medida afirmativa y/o principio de paridad de género en cada estado hasta el año en que se eligió a la legislatura correspondiente.

Se consideran tres variables para operacionalizar la explicación socioeconómica. Primero, para medir el nivel de desarrollo económico de cada entidad federativa se utiliza la variable "PIB per cápita estatal", que mide el producto interno bruto per cápita de las entidades federativas a precios constantes de 2013. ${ }^{19}$ Segundo, para medir el grado de urbanización en las 32 entidades, se usa la variable "Urbanización", la cual indica el porcentaje de población de cada entidad que vive en comunidades urbanas. ${ }^{20}$ Tercero, para medir el nivel educativo de cada entidad, se considera la variable Educación superior. Esta variable mide el porcentaje de la población de 15 años y más con al menos un año aprobado en estudios de nivel superior. ${ }^{21}$

Por último, se incluye la variable "Alternancia política partidista" como una variable de control. Esta variable es dicotómica y mide la ocurrencia o no de la alternancia en el partido que gobierna la entidad correspondiente antes de que se eligiera e integrara cada legislatura. La Tabla 2 resume las decisiones metodológicas relacionadas con las variables presentadas en esta sección.

19 Se considera el PIB per cápita estatal y no el Índice de Marginación del Consejo Nacional de Población porque mientras que para la primera se cuenta con mediciones anuales para todo el período analizado, para la segunda las mediciones son quinquenales a partir de 1995, por lo cual solo se contaría con cinco mediciones para los 32 años analizados.

20 De acuerdo con el INEGI, una población se considera rural cuando tiene menos de 2,500 habitantes, mientras que la urbana es aquella donde viven más de 2,500 personas. Ver, por ejemplo, https:/ / bit.ly/39hLKgZ, https:/ / bit.ly/3t6kgTd (página 9) o https:/ /bit.ly/3ckx7eQ (lámina 13)

21 Tanto el porcentaje de población urbana como el porcentaje de la población con educación superior son variables que el INEGI levantó cada cinco años en censos, conteos poblacionales y una encuesta intercensal. Mientras que el porcentaje de población urbana tiene seis mediciones temporales (1990, 1995, 2000, 2005, 2010 y 2015), el porcentaje de la población con educación superior solo tiene cuatro (2000, 2005, 2010 y 2015). Para hacer la unión con la base de dato general, en donde las variables tienen una temporalidad anual, se adoptó el siguiente criterio: asignar el dato de un levantamiento de información (p. ej., 1990) al año del levantamiento (1990), así como a los dos años previos y posteriores (1988, 1989, 1991 y 1992). La idea es que el valor de la medición sea lo más vigente posible en términos temporales. La única excepción es para las observaciones del porcentaje de población urbana de 1987, porque el INEGI no llevó a cabo un conteo de población en 1985. Por lo tanto, para este año se usa la información del censo de 1990. 


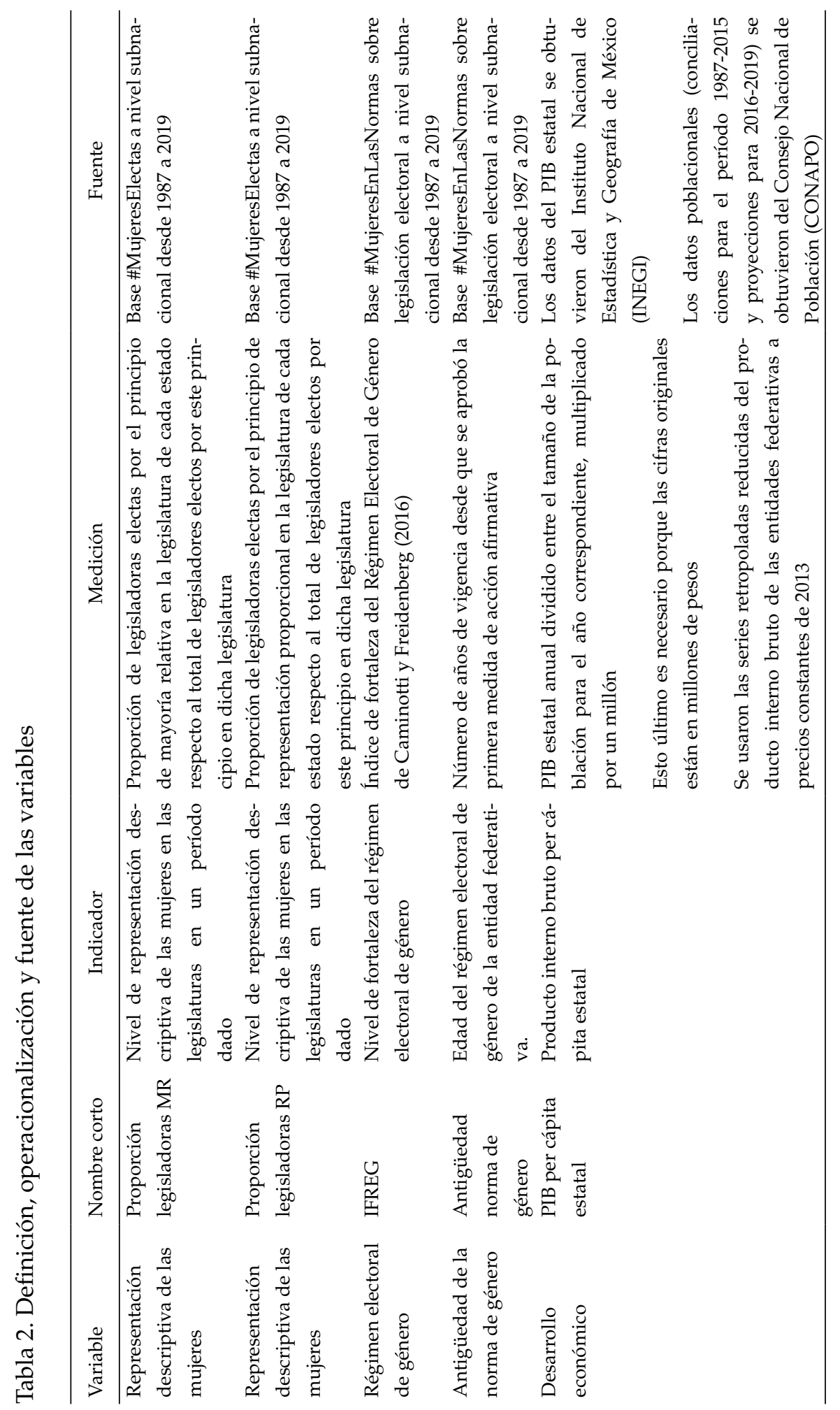




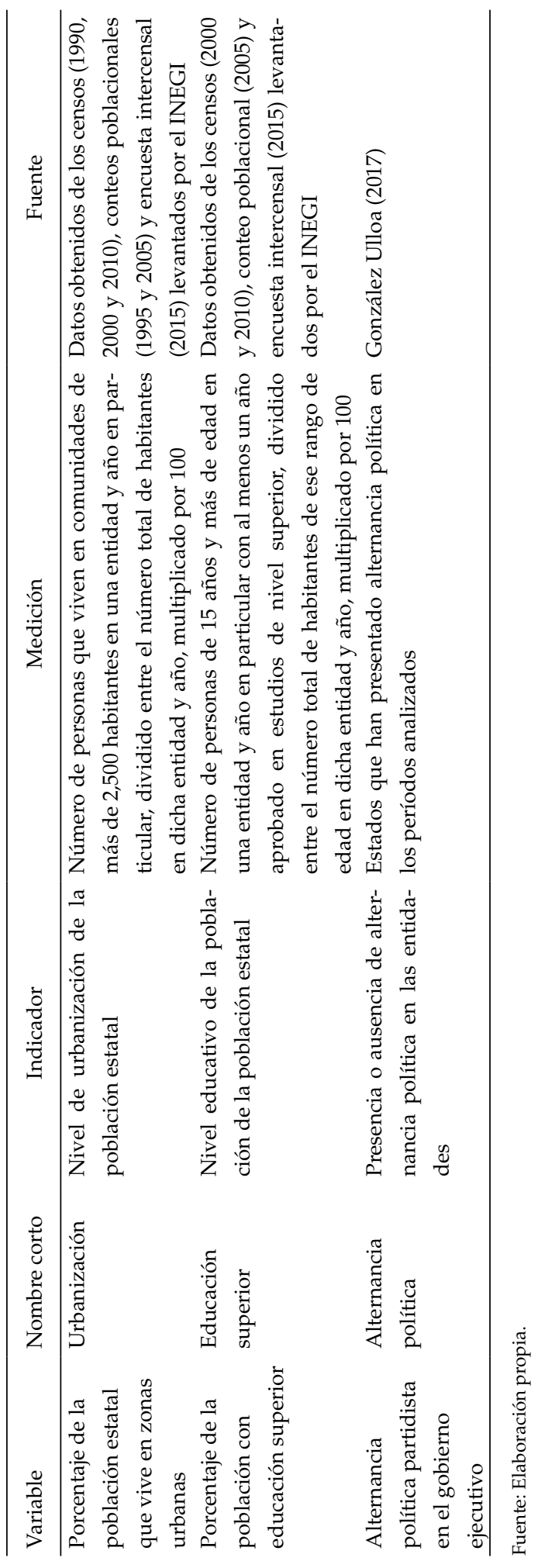




\section{ANÁLISIS DESCRIPTIVO}

El objetivo de esta sección es presentar el análisis descriptivo que constata que los resultados de la representación son disímiles por entidad y a través del tiempo (comparación sincrónica y diacrónica). Como ilustra la Figura 2, a lo largo de las tres últimas décadas, el nivel de representación política descriptiva de las mujeres a nivel legislativo en las entidades federativas mexicanas se ha incrementado, en promedio, 38.5 puntos porcentuales. ${ }^{22}$ La progresiva y sostenida reducción de la brecha de género entre legisladores y legisladoras locales no es una cuestión menor. Este resultado es producto del esfuerzo realizado por múltiples actores críticos (sociales, políticos y judiciales) que han trabajado para incrementar los requisitos que debían cumplir los partidos en el registro de candidaturas.

Figura 2. Porcentaje promedio de mujeres y hombres en las legislaturas de las entidades federativas electos tanto por el principio de mayoría relativa como de representación proporcional, 1991-2019

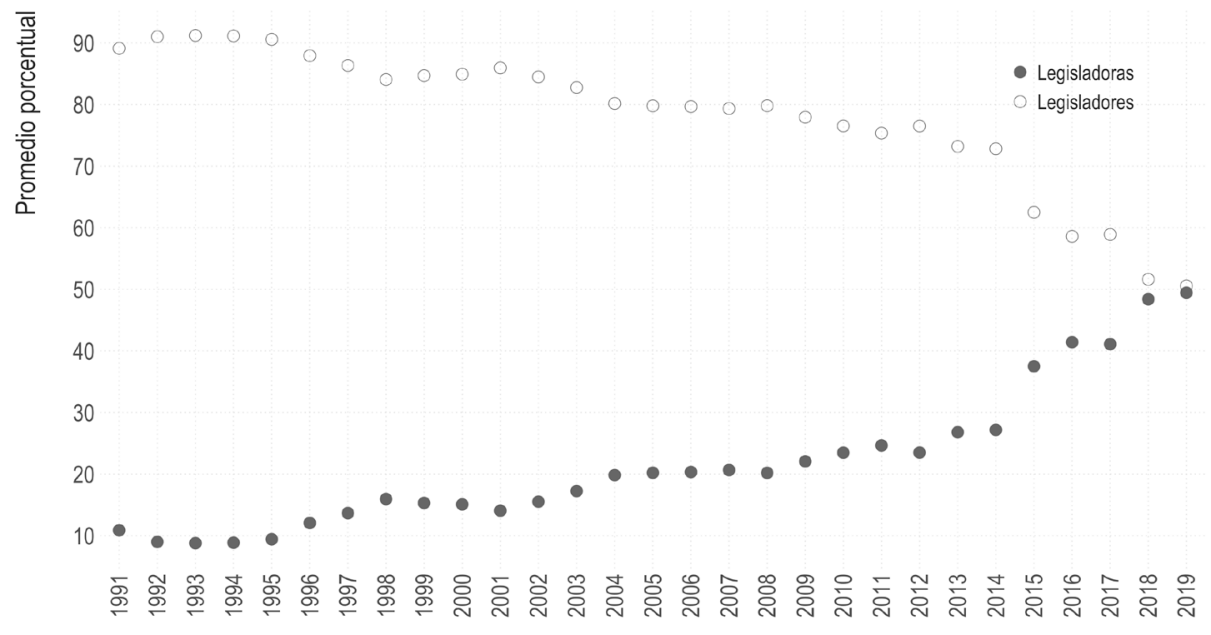

Fuente: Elaboración propia.

Nota: La gráfica comienza en 1991 porque es el primer año para el que se tienen datos de al menos un tercio de las entidades federativas (12 de 32 ).

$\mathrm{Al}$ analizar la evolución del porcentaje de legisladoras en cada entidad (Figura 3), los datos revelan variaciones interesantes tanto en el punto de arranque de

22 $\quad \mathrm{Al}$ analizar esta gráfica, es importante tener presente que es a partir de 2001 cuando se incluyen los datos de todos los estados para calcular los promedios de legisladoras y legisladores locales. Antes de este año el número de entidades consideradas oscila entre 12 y 29. A pesar de los esfuerzos realizados por el equipo de investigación por contar con el mayor número de datos por legislatura, no fue posible conseguir dicha información para todos los estados desde 1987. 
cada serie (comparar, por ejemplo, la primera observación de Nayarit o Tabasco respecto al primer dato de la Ciudad de México), como las diferencias en el ritmo y dirección en la tendencia de crecimiento del porcentaje de diputadas locales de una legislatura a otra, incluso dando cuenta de casos donde el camino no ha sido lineal sino de avances y retrocesos (como puede verse, por ejemplo, en Aguascalientes, Morelos, Nuevo León o Puebla). ${ }^{23}$

Los diferentes ritmos de la representación de las legisladoras evidencian también dos elementos significativos: por un lado, las resistencias de las élites políticas y de los diversos actores estatales respecto a darle espacios en las candidaturas a las mujeres (resulta imposible ser electa sino se está de manera previa nominada como candidata por el partido) y, por el otro, la capacidad de articulación y presión de las mujeres políticas de cada entidad para exigir que se cumplan las reglas electorales, crear nuevas reglas o, en su caso, fortalecer las existentes. Morelos es un excelente ejemplo en ese sentido. El zigzagueo en los niveles de representación descriptiva da cuenta de las pujas por el poder político en el acceso al espacio legislativo, que luego se han expresado de manera clara en el esfuerzo que las mujeres han realizado para ejercer sus cargos en igualdad de condiciones que los hombres. La experiencia de la última legislatura (2018-2021), donde la mayoría del Congreso es femenino (14 de 20) y ningún cargo de autoridad ejercido por mujeres, es evidencia de ello.

A pesar de estas diferencias, la Figura 3 muestra también que el mayor crecimiento en el porcentaje de legisladoras locales se dio fundamentalmente en los últimos cinco años, tras la aprobación y exigencia de cumplimiento del principio constitucional de la paridad de género en cada entidad (2014) y, específicamente, al reforzarse dicho principio con una mayor voluntad política de los OPLES y del INE en exigir que los partidos cumplan con los lineamientos específicos que se habían diseñado para establecer el modo en que debían integrar las candidaturas a los cargos de representación popular (2017). Como resultado, al comienzo de la última legislatura para la cual se cuenta con datos en la mayor parte de las entidades, las mujeres ganaron aproximadamente el $50 \%$ de las diputaciones y en algunos casos esa cifra es mayor al 60\% (ver los casos de Chiapas o de Morelos).

23 Las líneas de cada entidad abarcan los años para los cuales se logró recabar información. Por ello, el que no haya línea en los primeros años de una gráfica no necesariamente significa que el porcentaje de mujeres electas sea 0 , dado que no se cuenta con información para el período correspondiente. 
Figura 3. Porcentaje de mujeres en las legislaturas de las entidades federativas electas tanto por los principios de mayoría relativa y proporcional, 1987-2019

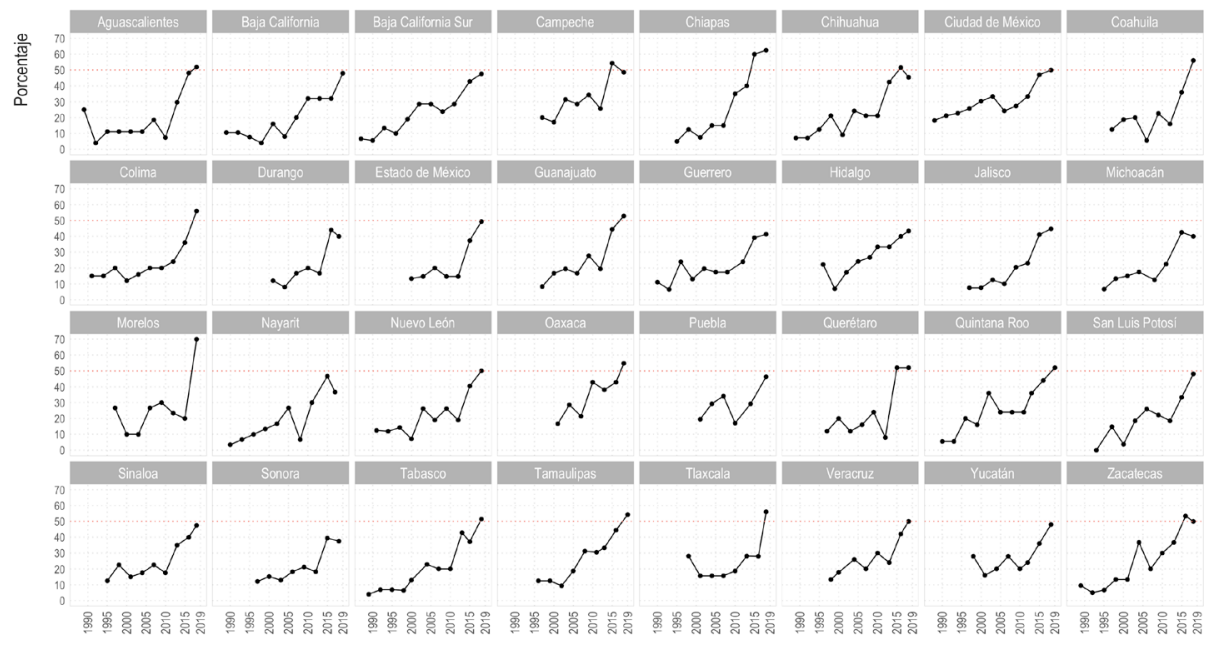

Fuente: Elaboración propia.

La Figura 4 muestra que del mismo modo que a nivel nacional, la ingeniería electoral ha creado oportunidades para que las mujeres puedan acceder a una candidatura en condiciones más competitivas e incluyentes en las entidades

Figura 4. Evolución del Índice de Fortaleza del Régimen Electoral de Género en las entidades federativas, 1994-2016

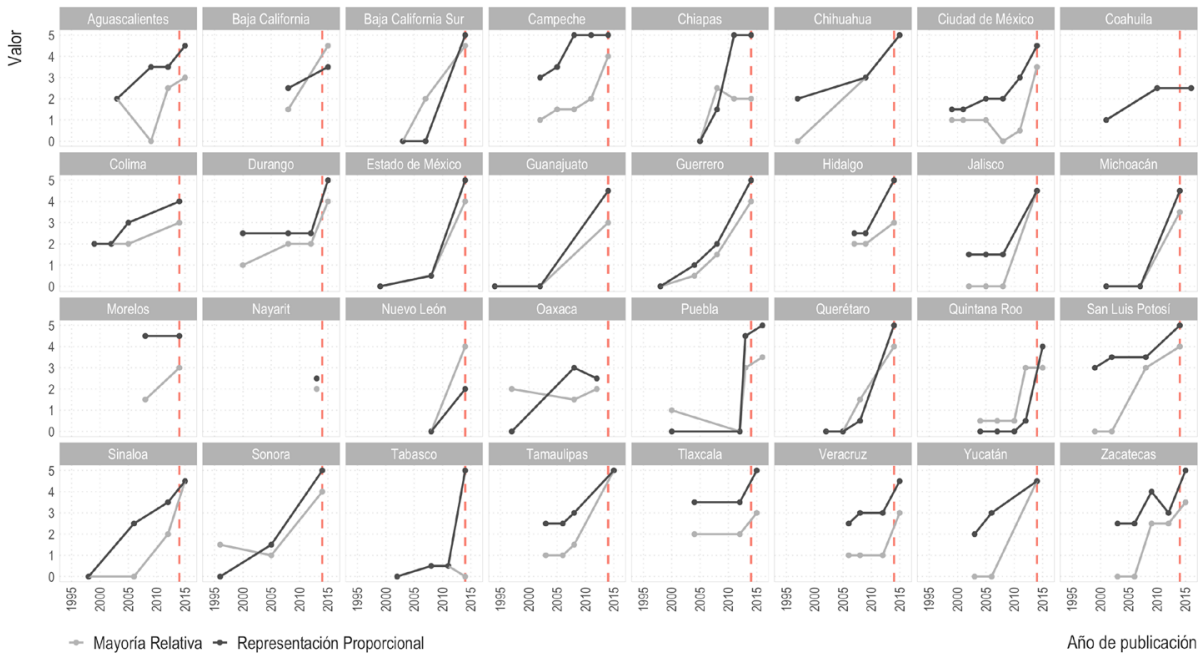

Fuente: Elaboración propia. 
federativas del país, unas veces originadas desde las entidades (como fue el caso de Chihuahua en 1994) y otras por impulso de la federación (como la reforma electoral de la paridad de género en 2014), cuando buscó nacionalizar el sistema electoral.

La evolución del régimen electoral de género mexicano en el nivel subnacional debe analizarse en dos etapas: a) la del federalismo electoral y b) la de la nacionalización electoral. En la primera fase, las reglas electorales varían considerablemente de un estado a otro y entre los principios electorales de mayoría relativa y representación proporcional al interior de un mismo estado, ya que el tamaño de las cuotas, el tipo de sanciones o la existencia de mandatos de posición era heterogénea. Además, en esa primera fase de federalismo electoral el nivel de ambigüedad de las reglas era bastante común, dado que los partidos dejaban lagunas o vacíos que permitían una interpretación más laxa de esas reglas. ${ }^{24}$ La segunda fase comienza en 2014 (línea roja vertical en la Figura 4) con el proceso de nacionalización en el que la Federación exige que las entidades reformen sus regímenes electorales de género de manera homogénea a las reglas federales, los requisitos a los partidos respecto al registro de candidaturas comienzan a armonizarse en todas las unidades territoriales $\mathrm{y}$, al mismo tiempo, tienden a cerrarse los espacios de interpretación y la ambigüedad de las reglas, ya sea por la acción de las autoridades electorales administrativas (los OPLES) como por las decisiones de las autoridades judiciales.

\section{MODELOS}

En esta sección se presentan los diversos modelos para entender qué factores son los más relevantes para explicar los diferentes niveles de representación descriptiva de las mujeres a nivel subnacional. ${ }^{25}$ La naturaleza de los datos analizados plantea diferentes retos y complicaciones para su modelado con técnicas tradicionales. Por un lado, las dos versiones de la variable dependiente no solo son proporciones, sino que son proporciones para las cuales el denominador puede cambiar de una legislatura a otra. ${ }^{26}$ Por otro lado, es muy probable que las observaciones de cada entidad estén correlacionadas. Asimismo, dado que el número de legislaturas consideradas para cada estado es diferente, la base de datos tiene una estructura de panel no balanceado. Si estos factores no

24 Caminotti y Freidenberg (2016) sostienen que además la redacción de las normas hasta 2014 era ambigua, su aplicación estaba sujeta a la interpretación de las élites y había casos donde no estaba contemplado que quien no respeta la ley no pudiera registrar candidaturas. Esto fue cambiando a partir de la aprobación de las reglas de la paridad de género en la Constitución, en parte, por la actuación del movimiento de mujeres, así como también por el papel de las autoridades administrativas y jurisdiccionales, federales y estatales, que fueron resolviendo los conflictos y las demandas cada vez más a favor de la protección de los derechos políticos-electorales de las mujeres.

25 Tanto los datos, como el código y las gráficas utilizadas en esta investigación pueden ser consultados en el siguiente repositorio: https://github.com/segasi/donde_ganan_las_mujeres.

26 Durante el período analizado el número total de curules de mayoría relativa y representación proporcional se modificó una o más veces en al menos 18 entidades. 
son tomados en cuenta, pueden afectar las estimaciones y, particularmente, la incertidumbre alrededor de las mismas. ${ }^{27}$

Partiendo de este diagnóstico, se optó por utilizar modelos binomiales con función de enlace logística (también conocidos como modelos logísticos binomiales) estimados a través del paquete $\{1 \mathrm{me} 4\}$ de R. Si bien el uso más común de los modelos con enlace logístico es cuando la variable de respuesta es dicotómica, con valores de 0 y 1, también es adecuado y recomendable cuando el proceso generador de la variable de respuesta es binomial y, por lo tanto, ésta es una proporción con valores entre 0 y 1 (Gelman y Hill 2007: 116; Chen et al. 2017). ${ }^{28}$

Todas las especificaciones utilizadas consideran de forma conjunta las observaciones de las 32 entidades para estimar el efecto que tiene cada una de las variables explicativas en el valor esperado de la proporción de legisladoras electas por el cada principio en todas las entidades (efectos fijos), así como el efecto de IFREG en dichas proporciones para cada entidad por separado (efectos aleatorios). ${ }^{29}$ En los modelos 3, 4, 5, 7 y 8 se considera el efecto de PIB per cápita estatal, Urbanización y Educación superior al estimar tanto los efectos fijos como los aleatorios.

La Tabla 4 presenta ocho especificaciones diferentes del modelo. En las primeras cuatro la variable dependiente es la proporción de legisladoras electas por el principio de mayoría relativa y en las últimas cuatro es la proporción de legisladoras electas por el principio de representación proporcional. Dado que el denominador para calcular estas proporciones puede cambiar de una legislatura a otra en el mismo estado, al momento de programar los modelos la variable dependiente fue definida en términos del número de legisladoras electas por cada principio en cada legislatura (número de éxitos) y el número total de curules electas por dicho principio (número de ensayos). ${ }^{30}$

Las ocho especificaciones de los modelos incluyen al IFREG MR o RP, respectivamente, como principal variable explicativa (hipótesis 1). Los modelos 2 a 4 y 6 a 8 incluyen también la variable Antigüedad norma de género (hipótesis 2). ${ }^{31}$ Con el fin de analizar empíricamente la validez de las dos hipótesis polí-

$27 \quad$ Un problema potencial adicional es que los factores que explican la probabilidad de que una candidata mujer sea electa también podrían explican los cambios en el IFREG durante el tiempo. Atender este tema está fuera de los alcances de esta investigación, pero forma parte de nuestra agenda futura.

28 De acuerdo con Chen et al., "la regresión logística, un modelo lineal generalizado común, es adecuado para un resultado binomial, donde la proporción es calculada como la razón del número de eventos objetivos [i.e., éxitos] respecto al número total de ensayos, 'ny de n'” (2017: 2).

$29 \quad$ La Tabla A en el anexo ofrece estadísticas descriptivas de las variables consideradas en los modelos.

30 Por ejemplo, en la legislatura de 2006 a 2009 de Nuevo León se eligieron seis legisladoras de mayoría relativa y el total de diputaciones electas por este principio fue 26. Al estimar el modelo calcula la proporción correspondiente $(6 / 26)$, que equivale a 0.23 .

31 La correlación entre IFREG y Antigüedad de la norma de género es moderada: oscila entre 0.43 y 0.63 , dependiendo de la versión de IFREG que se considere (MR o RP) y el coeficiente utilizado (Pearson, Spearman o Kendall). Partiendo de las recomendaciones de Arceneaux y Huber (2007) y Gujarati y Porter (2010: 245273), se decidió no excluir la variable Antigüedad norma de género de los diversos modelos en donde es considerada. Como explican los autores recién mencionados, si un modelo está correctamente especificado (como creemos que es el caso de los nuestros) la multicolinealidad no provoca que los estimadores de los coeficientes de las variables correlacionadas sean sesgados, sino que las estimaciones de estos sean menos 
tico-institucionales a la par de las tres hipótesis socioeconómicas, los modelos 3, 4, 7 y 8 incluyen una versión reescalada de PIB per cápita estatal ${ }^{32}$ (hipótesis 3). Asimismo, los modelos 4 y 8 incluyen también las variables Urbanización (hipótesis 4) y Educación Superior (hipótesis 5). Los ocho modelos incluyen también dos variables de control. Primero, la variable de respuesta rezagada un período para controlar por la posible correlación temporal en la proporción de mujeres electas por cada principio entre una legislatura y otra. Segundo, la variable que mide la ocurrencia o no de Alternancia en el partido que controla el respectivo poder ejecutivo estatal.

\section{Tabla 4. Modelos}

\begin{tabular}{ccccccccc}
\hline & \multicolumn{3}{c}{ Mayoría relativa } & \multicolumn{5}{c}{ Representación proporcional } \\
\hline & Modelo 1 & Modelo 2 & Modelo 3 & Modelo 4 & Modelo 5 & Modelo 6 & Modelo 7 & Modelo 8 \\
\hline IFREG & $0.213^{* * *}$ & $0.160^{* * *}$ & $0.155^{* * *}$ & $0.156^{* * *}$ & $0.108^{* * *}$ & $0.081^{* * *}$ & $0.082^{* * *}$ & $0.072^{* *}$ \\
& $(0.027)$ & $(0.036)$ & $(0.036)$ & $(0.038)$ & $(0.021)$ & $(0.028)$ & $(0.029)$ & $(0.029)$ \\
Antigüedad norma & & $0.026^{* * *}$ & $0.028^{* * *}$ & $0.021^{* *}$ & & 0.008 & 0.008 & 0.006 \\
de género & & $(0.010)$ & $(0.010)$ & $(0.010)$ & & $(0.008)$ & $(0.008)$ & $(0.009)$ \\
PIB per cápita & & & $0.499^{*}$ & 0.451 & & & -0.057 & -0.050 \\
estatal (reescalado) & & & $(0.289)$ & $(0.336)$ & & & $(0.333)$ & $(0.359)$ \\
Urbanización & & & & -0.008 & & & & -0.007 \\
& & & & $(0.005)$ & & & & $(0.004)$ \\
Educación & & & & $0.033^{*}$ & & & & 0.016 \\
superior & & & & $(0.018)$ & & & & $(0.014)$ \\
Variable de & $1.193^{* * *}$ & $0.674^{*}$ & $0.616^{*}$ & $0.574^{*}$ & $1.119^{* * *}$ & $0.946^{* * *}$ & $0.946^{* * *}$ & $0.779^{* *}$ \\
respuesta rezagada a & $(0.292)$ & $(0.347)$ & $(0.349)$ & $(0.347)$ & $(0.292)$ & $(0.323)$ & $(0.323)$ & $(0.343)$ \\
Alternancia & 0.100 & -0.004 & 0.021 & 0.028 & 0.079 & 0.079 & 0.076 & 0.089 \\
& $(0.073)$ & $(0.087)$ & $(0.089)$ & $(0.094)$ & $(0.077)$ & $(0.086)$ & $(0.087)$ & $(0.089)$ \\
Intercepto & $-2.124^{* * *}$ & $-2.081^{* * *}$ & $-2.131^{* * *}$ & $-2.001^{* * *}$ & $-1.770^{* * *}$ & $-1.700^{* * *}$ & $-1.695^{* * *}$ & $-1.377^{* * *}$ \\
& $(0.076)$ & $(0.104)$ & $(0.110)$ & $(0.320)$ & $(0.082)$ & $(0.111)$ & $(0.114)$ & $(0.258)$ \\
Núm. de & 256 & 182 & 182 & 182 & 255 & 182 & 182 & 182 \\
observaciones & & & & & & & & \\
Log Likelihood & -507.824 & -366.267 & -365.010 & -362.710 & -420.855 & -315.099 & -315.084 & -313.901 \\
AIC & $1,029.649$ & 748.534 & 754.020 & 771.420 & 855.711 & 646.198 & 654.168 & 673.802 \\
BIC & $1,054.465$ & 774.166 & 792.469 & 845.113 & 880.500 & 671.830 & 692.616 & 747.494 \\
\hline
\end{tabular}

Errores estándar entre paréntesis. ${ }^{*} \mathrm{p}<0.1 ;{ }^{* *} \mathrm{p}<0.05 ;{ }^{* * *} \mathrm{p}<0.01$ Fuente: Elaboración propia.

precisas (i.e., el error estándar de las estimaciones de las variables correlacionadas es más grande). Si bien la inclusión de la variable Antigüedad norma de género efectivamente aumenta el error estándar de IFREG en los modelos 2 a 4 y 6 a 8 de nuestro artículo, en estos seis modelos los coeficientes de IFREG siguen siendo estadísticamente significativos a, cuando menos, el $1 \%(\mathrm{p}<0.01)$. Si excluyéramos Antigüedad norma de género de los modelos 2 a 4 y 6 a 8, esto no solo provocaría que dichos modelos estuvieran mal especificados, sino que incluso podríamos introducir un sesgo en la estimación de los coeficientes de IFREG. La misma lógica se siguió en el caso de Urbanización y Educación superior, cuya correlación oscila entre 0.45 y 0.61 , dependiendo del coeficiente que se utilice.

32 Esta versión de PIB per cápita estatal tiene valores entre 0 y 1 . La transformación es sugerida por el paquete $\{\mathrm{lme} 4\}$ porque las unidades originales de la variable (pesos) son mucho mayores a la del resto de las variables explicativas. 
Los resultados en la Tabla 4 muestran que el efecto del IFREG MR o RP es positivo y estadísticamente significativo en todos los modelos. La magnitud del coeficiente de esta variable se reduce de manera importante cuando se incluye la variable Antigüedad norma de género en la especificación (modelos 2 a 4 y 6 a $8)$, pero -como se explica más adelante- sigue representando un efecto sustantivo. Vale la pena resaltar que el coeficiente de IFREG MR es aproximadamente el doble que el de IFREG RP en especificaciones similares. Los coeficientes de Antigüedad norma de género son positivos en todas las especificaciones, pero solo son estadísticamente significativos en los modelos 2, 3 y 4 .

En el caso de PIB per cápita estatal, además de que sus coeficientes no son estadísticamente significativos a niveles convencionales, ${ }^{33}$ el signo de las estimaciones cambia dependiendo de si la variable de respuesta es la proporción de mujeres electas por el principio de mayoría relativa o representación proporcional (comparar modelos 3 y 4 respecto a 7 y 8). Por su parte, el signo de los coeficientes de Urbanización y Educación superior es consistente en los modelos 4 y 8, pero, contrario a lo propuesto en la hipótesis 4, en el caso de Urbanización es negativo en ambas especificaciones. Además, los coeficientes de estas dos variables no son estadísticamente significativos a niveles convencionales. ${ }^{34}$

Los coeficientes de la variable de respuesta rezagada son positivos en todos los modelos, pero estadísticamente significativos a niveles convencionales solo en los modelos 1, y 5 a 8. Estos resultados confirman que la proporción de diputadas de mayoría relativa o representación proporcional electas en una legislatura está correlacionada positivamente con la proporción de mujeres electas en la legislatura previa. Por último, los coeficientes de la variable Alternancia Política son positivos en todos los modelos (excepto el 2), pero no alcanzan niveles de significancia estadística convencionales.

Las Figuras 5 y 6 ofrecen una representación visual del significado sustantivo de los coeficientes de IFREG (ambas gráficas) y Antigüedad norma de género (primera gráfica). La Figura 5 presenta las predicciones sobre la proporción de legisladoras de mayoría relativa (columna izquierda) y representación proporcional (columna derecha) electas para cada nivel de IFREG (renglón superior) y Antigüedad norma de género (renglón inferior). Estas predicciones fueron calculadas a partir de los coeficientes de efectos fijos estimados para cada variable en los modelos 2 y $6{ }^{35}$ La línea negra en las cuatro gráficas representa la proporción de legisladoras electas por el principio correspondiente y las líneas grises que las rodean representan el respectivo intervalo de confianza al 95\% de confianza.

$33 \quad$ En el modelo 3 el p-value es 0.08389 .

34 El coeficiente de Educación superior tiene un p-value de 0.0680 en el modelo 4 . Si en este mismo modelo se excluye IFREG de la especificación, los coeficientes de Urbanización y Educación superior mantienen el signo descrito antes y son estadísticamente significativos al $5 \%$ o mejor.

35 Se eligieron estos modelos para calcular las predicciones porque son los que tienen los valores más bajos de AIC y BIC. 
Figura 5. Predicciones de proporciones de legisladoras de mayoría relativa y representación proporcional a partir de los coeficientes de efectos fijos de IFREG y la antigüedad de la primera norma de género

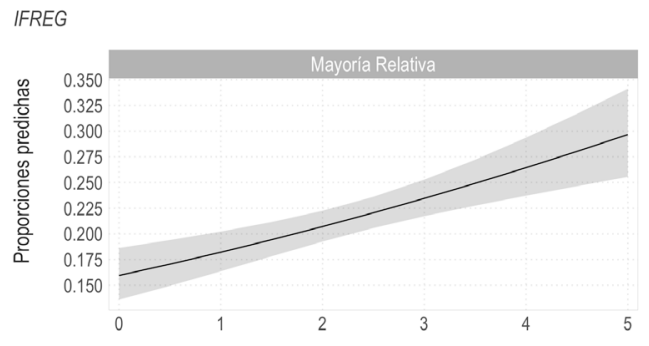

Antigüedad de la primera norma de género

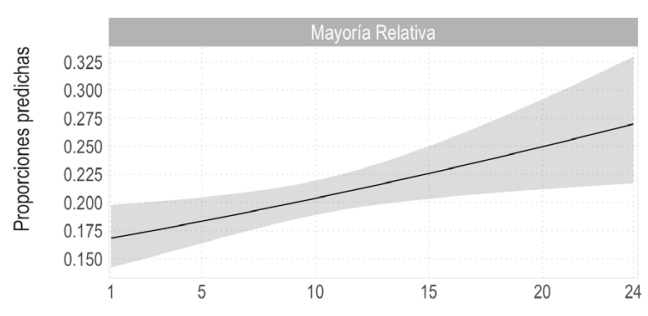

Fuente: Elaboración propia.
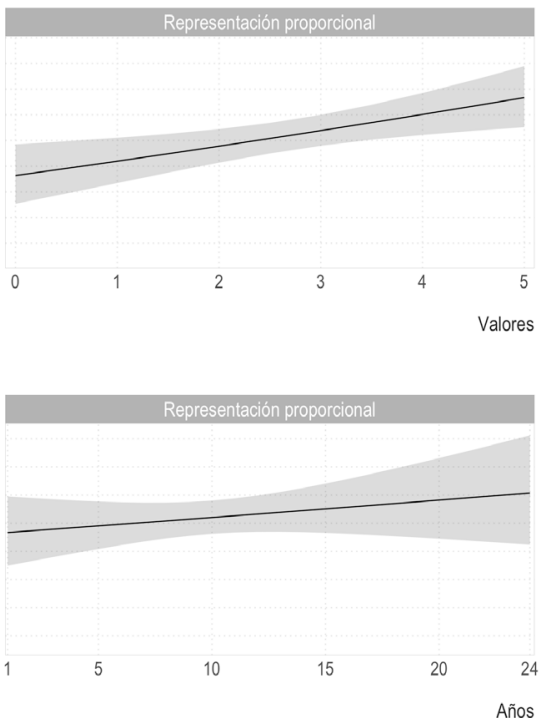

La Figura 5 muestra que cuando la variable de respuesta es la proporción de legisladoras de mayoría relativa, un incremento del IFREG de 0 a 5 (es decir, de su valor mínimo al máximo) está asociado a un crecimiento de $85.6 \%$ de la proporción predicha (de 0.160 a 0.297 ). ${ }^{36}$ En el caso de las legisladoras de representación proporcional el modelo predice un incremento de $35.2 \%$ en la proporción de legisladoras electas (de 0.216 a 0.292) ante un cambio similar en los valores del IFREG.$^{37}$ Esta diferencia es consistente con los resultados de la Tabla 4. Aunque este resultado debe ser analizado y explicado con mayor detalle en etapas futuras de este proyecto de investigación, es factible que la diferencia en la magnitud del efecto de IFREG en la proporción de mujeres electas por cada principio se deba a las condiciones iniciales en cada uno de ellos.

Durante los primeros años del período analizado el porcentaje de legisladoras electas por el principio de representación proporcional (respecto al total de escaños electos por este principio) fue mayor al porcentaje de legisladoras electas por el principio de mayoría relativa en la mayor parte de los estados. Esto, a su vez, probablemente provocó que las mejoras en el régimen electoral de género

36 Para estas predicciones el valor del resto de las variables es fijado en su respectiva media: 0.23 para la variable de respuesta rezagada y 10.1 para la variable de Antigüedad norma de género.

37 En esta predicción el valor del resto de las variables es fijado en su respectiva media: 0.30 para la variable de respuesta rezagada y 9.93 para Antigüedad norma de género. 
tuvieran un menor impacto en el porcentaje de mujeres electas por el principio plurinominal. Esto parece ser respaldado por las predicciones mostradas en los dos paneles superiores de la Figura 5. Mientras que la proporción predicha de mujeres electas cuando IFREG toma un valor de 5 es muy parecida para ambos principios (0.297 para mayoría relativa y 0.292 para representación proporcional), cuando IFREG es 0 la proporción predicha de mujeres electas por el principio plurinominal es 35\% mayor que en el caso de mayoría relativa $(0.216$ y 0.160 , respectivamente). El panel inferior izquierdo de la Figura 5 ilustra la magnitud del efecto de la Antigüedad norma de género cuando la variable de respuesta es la proporción de legisladoras de mayoría relativa. ${ }^{38}$ Mientras que la proporción predicha es de 0.168 cuando la antigüedad es de un año (valor mínimo), aumenta a 0.270 cuando la primera norma de género tiene 24 años (valor máximo).

La Figura 6 muestra, por último, que el efecto de IFREG no es homogéneo entre entidades. Mientras que las líneas negras representan las predicciones de la proporción de legisladoras de mayoría relativa electas en cada entidad para los diferentes niveles del IFREG MR, calculadas a partir de los coeficientes de efectos aleatorios estimados en el modelo $2,{ }^{39}$ las líneas rojas ilustran la misma predicción, pero utilizando los efectos fijos de este modelo. Si bien la pendiente de todas las líneas negras es positiva, las diferencias en las magnitudes de estas son sustantivas. Por ejemplo, mientras que en la Ciudad de México un cambio de 0 a 5 en el IFREG está asociado con un incremento de 0.072 en la proporción de mujeres electas por este principio (de 0.214 a 0.286), en Querétaro el aumento es de más del doble $(0.179$, de 0.125 a 0.304$)$.

38 En esta predicción el valor del resto de las variables es fijado en su respectiva media: 1.89 para IFREG y 0.23 para la variable de respuesta rezagada.

39 Estas predicciones fueron calculadas a partir de los coeficientes de efectos aleatorios estimados en el modelo 2. Para ello, el valor del resto de las variables es fijado en su respectiva media: 0.23 para la variable de respuesta rezagada y 10.1 para Antigüedad norma de género. 
Figura 6. Predicciones de proporciones de legisladoras de mayoría relativa a partir de los coeficientes de efectos aleatorios de IFREG

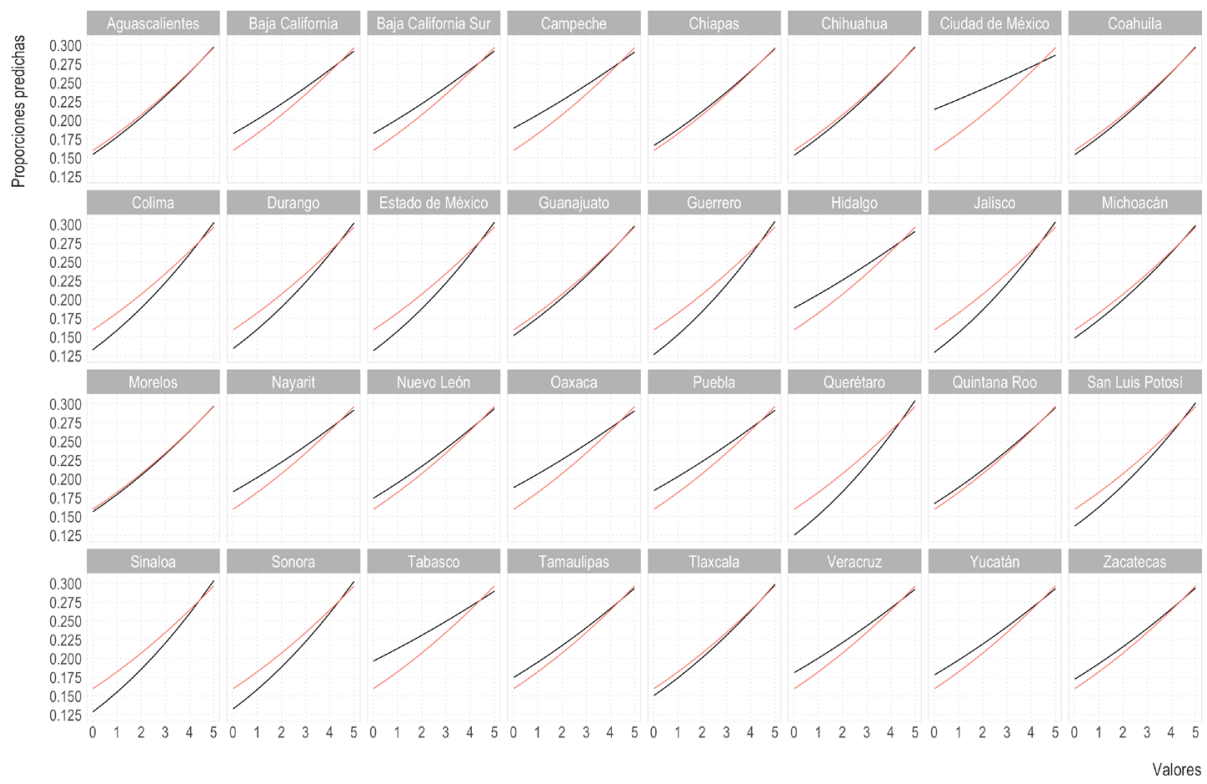

Fuente: Elaboración propia.

\section{VII.CONCLUSIONES}

Las oportunidades de acceso a la representación política de las mujeres políticas a nivel subnacional no dependen de un mayor nivel socioeconómico, del nivel de alternancia política o de condiciones más igualitarias de distribución de los recursos, sino del diseño de las reglas formales y su nivel de fortaleza en su interacción con el sistema electoral (explicación política-institucional). En consonancia con investigaciones previas, este análisis da cuenta de la conexión multinivel entre niveles de competencia, por la interacción de los esfuerzos normativos para armonizar la legislación y hacer que los partidos encuentren incentivos y restricciones similares en la diversidad de unidades subnacionales que integran el sistema político mexicano.

Este trabajo contribuye metodológica y empíricamente a evidenciar a nivel subnacional una serie de argumentos que se habían esgrimido sobre la competencia nacional pero que, al no contar con los datos de las reglas electorales y de la representación política legislativa de las entidades federativas en un período extenso de tiempo, era imposible conocer cómo afectaban las reglas la representación descriptiva de las mujeres. Una de las principales contribuciones metodológicas que realiza este estudio es la aplicación de una manera novedosa de evaluar las reglas de registro de candidaturas a través del "Índice de fortaleza del régimen electoral de género", que fue originalmente creado por Caminotti y Freidenberg (2016) para evaluar las reglas de juego estatales mexi- 
canas y provinciales argentinas para un momento (2013) y que fue aplicado por Flores Ivich y Freidenberg (2017) y por Freidenberg y Alva Huitrón (2017) a las entidades mexicanas, a un universo mayor de reglas en un período de tiempo extenso (que no se había realizado hasta el momento), lo que ha permitido evaluar la relación entre estas variables y sus efectos con métodos estadísticos más sofisticados.

Este trabajo da cuenta del peso de los factores institucionales para reducir la brecha de género en las entidades federativas mexicanas a lo largo de treinta años (1987-2019) y genera una serie de insumos respecto a cómo debe continuar la agenda de investigación sobre representación política subnacional. La investigación da cuenta de que la reciente nacionalización del conjunto de reglas electorales que ha llevado a la armonización de las exigencias legales y normativas en el sistema político tras la reforma de 2014 ha tenido efectos positivos sobre la representación política de las mujeres mexicanas. Este estudio evidencia que cuanto mayor sea el nivel de fortaleza de las reglas electorales de género mayores serán los efectos positivos sobre la representación política de las mujeres. La hipótesis político-institucional planteada se corroboró y además el uso del método comparado subnacional mejoró nuestro conocimiento respecto al peso de diferentes variables sobre la representación de las mujeres. El método comparado subnacional no sólo aumentó el número de observaciones, sino que además permitió controlar variables contextuales, lo que sería muy difícil en la comparación entre países.

En consonancia con los hallazgos recientes de diferentes investigaciones de la política comparada (Giraudy et al. 2019; Harbers y Steele 2020), este estudio evidencia las diferencias existentes en el respeto de los derechos en el territorio y cómo las mujeres mexicanas han enfrentado condiciones adversas para ejercer su ciudadanía dependiendo de la entidad federativa en la que residían. Los datos muestran que la distribución de bienes públicos y el acceso a los derechos no ha sido homogénea para hombres y para mujeres en cada unidad territorial en el tiempo. Precisamente, la reducción de la brecha de género supone un factor de democratización subnacional en cualquier sistema político y busca evidenciar una cada vez mayor homogeneidad en la extensión de los derechos y el acceso a la representación política. Este sesgo de género ratifica la idea de la presencia de ciudadanas mexicanas de primera o de segunda en función de su lugar de residencia, así como también de la heterogeneidad de obstáculos que ellas enfrentan cuando quieren hacer política.

Este estudio también llama la atención sobre la necesidad de incluir en la agenda de investigación futura variables no institucionales que permitan reforzar el análisis de la representación política de las mujeres y sus derechos de manera multidimensional. Esta es una limitación que en el caso de este estudio no pudo subsanarse debido a la ausencia de datos para las últimas tres décadas de competencia política a nivel subnacional. La agenda deberá explorar la capacidad de las mujeres partidistas, la acción del movimiento feminista y del movimiento amplio de mujeres para denunciar las prácticas de simulación de 
los partidos políticos en las diferentes entidades federativas (Piscopo 2016). A partir de esta estrategia de movilización política, que hace que la justicia electoral pueda intervenir en la resolución de los conflictos en torno al cumplimiento de los derechos políticos-electorales de los individuos, las mujeres han logrado vencer algunos obstáculos legales que impedían el cumplimiento del régimen electoral de género e incluso situaciones de violencia política en razón de género. Este tipo de análisis evidencia la necesidad de impulsar investigaciones que permitan medir esa capacidad de movilización jurídica en los estados, dado que -como se ha evidenciado en otros estudios- el régimen electoral se ha fortalecido con el accionar de la justicia electoral y esto -a su vez- ha impactado en la representación política de las mujeres.

Finalmente, la agenda de investigación-acción tiene que explorar el comportamiento estratégico de los actores partidistas y la capacidad de autonomía política de las mujeres sobre los niveles de representación política. Si bien la conexión entre partidos y diseños institucionales ha sido explorada en términos formales, aún falta profundizar más en las razones y en los modos concretos en que se dan las prácticas informales sobre los procesos de selección de candidaturas o sobre el modo en que se hacen campañas electorales. Esas instituciones informales funcionan como candados sobre la dinámica organizativa de los partidos y limitan la participación política de las mujeres. Más allá de estas oportunidades de continuar enriqueciendo la investigación comparada, este trabajo evidencia el modo en que las reformas políticas orientadas a facilitar el acceso de las mujeres a las instituciones democráticas han supuesto un paso importante en la reducción de la brecha de género en la política subnacional mexicana y en la eliminación de los obstáculos que reproducen las desigualdades estructurales de las sociedades.

\section{BIBLIOGRAFÍA}

Alanis Figueroa, María del Carmen. 2017. "Contributions of Electoral Justice to the Strengthening of Women's Political Rights: The Case of Mexico in Comparative Perspective." En Women, Politics and Democracy in Latin America, editado por Tomáš Došek, Flavia Freidenberg, Mariana Caminotti y Betilde Muñoz-Pogossian. Nueva York: Palgrave MacMillan, 153-163.

Alles, Santiago. 2018. “Equilibrar el Terreno: Instituciones Electorales e Incorporación de Mujeres en las Legislaturas Provinciales en Argentina." En Mujeres en la política en América Latina: experiencias nacionales y subnacionales, editado por Flavia Freidenberg, Mariana Caminotti, Mariana, Betilde Muñoz-Pogossian y Tomáš Došek. México: Instituto Electoral de la Ciudad de México e Instituto de Investigaciones Jurídicas, UNAM, 193-222.

Arceneaux, Kevin y Gregory A. Huber. 2007. "What to Do (and Not Do) with Multicollinearity in State Politics Research." State Politics \& Policy Quarterly 7(1): 81-101.

Archenti, Nélida y María Inés Tula. 2017. "Critical Challenges of Quotas and Parity in Latin America." En Women, Politics and Democracy in Latin America, editado por Tomáš Došek, Flavia Freidenberg, Mariana Caminotti y Betilde Muñoz-Pogossian. Nueva York: Palgrave MacMillan, 29-44. 
Baldez, Lisa. 2004. "Elected Bodies: The Gender Quota Law for Legislative Candidate in Mexico." Legislative Studies Quarterly 2: 239-258.

Bareiro, Line y Soto, Lilian. 2015. La Hora de la Igualdad Sustantiva. New York: ONU Mujeres. Caminotti, Mariana. 2016. "Cuotas de Género y Paridad en América Latina: Mujeres, Partidos Políticos y Estado." En Reformas a las Organizaciones de Partido Políticos en América Latina (1978-2015), editado por Flavia Freidenberg y Betilde Muñoz-Pogossian. Lima: PUCP, OEA, SAAP e IIJ-UNAM, 183-203.

Caminotti, Mariana y Flavia Freidenberg. 2016. "Federalismo Electoral, Fortaleza de las Cuotas de Género y Representación Política de las Mujeres en los Ámbitos Subnacionales de Argentina y México." Revista Mexicana de Ciencias Políticas y Sociales 61 (228): 121141.

Caminotti, Mariana y Flavia Freidenberg. 2018. "Reformas Electorales Inclusivas en América Latina y Retos para la Igualdad Real de las Mujeres en la Política: una Introducción." En Mujeres en la política: Experiencias Nacionales y Subnacionales en América Latina, editado por Flavia Freidenberg, Mariana Caminotti, Betilde Muñoz-Pogossian y Tomáš Došek. México: Instituto Electoral de la Ciudad de México e Instituto de Investigaciones Jurídicas, UNAM, 7-32.

Comisión Económica para América Latina (CEPAL). 2020. Observatorio de Igualdad de Género en América Latina. Santiago de Chile: CEPAL. Disponible en: https://oig.cepal.org/ es/autonomias/autonomia-la-toma-decisiones

Comisión Interamericana de Mujeres (CIM). 2013. La Ciudadanía de las Mujeres en las Democracias de las Américas. Estocolmo y Washington: International IDEA y Comisión Interamericana de Mujeres, Organización de los Estados Americanos.

Cornelius, Wayne A., Todd Eisenstadt y Jane Hindley. eds. 1999. Subnational Politics and Democratization in Mexico. San Diego: Center for U.S. Mexican Studies, University of California.

Chen Kehui, Yu Cheng,Olga Berkout y Oliver Lindhiem. 2017. “Analyzing Proportion Scores as Outcomes for Prevention Trials: A Statistical Primer." Prevention Science 18(3): 312321.

Dahlerup, Drude y Leni Freidenvall. 2005. “Quotas as a 'Fast Track' to Equal Representation for Women: Why Scandinavia is No Longer the Model." International Feminist Journal of Politics 7(1): 26-48.

Flores Ivich, Georgina y Flavia Freidenberg. 2017. “¿Por qué las Mujeres Ganan en unas Legislaturas y no en otras? Una Evaluación de los Factores que inciden en la Representación Política de las Mujeres en las Entidades Federativas Mexicanas." En La Representación Política de las Mujeres en México, editado por Flavia Freidenberg. Ciudad de México: Instituto Nacional Electoral e Instituto de Investigaciones Jurídicas de la Universidad Nacional Autónoma de México, 101-152.

Franceschet, Susan, Mona Lena Krook y Jennifer Piscopo. eds. 2012. The Impact of Gender Quotas. Nueva York: Oxford University Press.

Freidenberg, Flavia. 2020. "Electoral Reform and Political Representation of Women in Latin America." En Oxford Research Encyclopedia of Politics. Retrieved 24 Nov., from https:/ / oxfordre.com/politics/view/10.1093/acrefore/9780190228637.001.0001/acrefore-9780190228637-e-1676.

Freidenberg, Flavia y Julieta Suárez-Cao. eds. 2014. Territorio y Poder: Nuevos Actores y Competencia Política en los Sistemas de Partidos Multinivel en América Latina. Salamanca: Ediciones Universidad de Salamanca

Freidenberg, Flavia y Karolina M. Gilas. 2020. En Nombre de los Derechos y a Golpe de Sentencias: el Impacto de la Justicia Electoral sobre la Representación Política de las Mujeres Mexicanas. Documento de Trabajo \#200. Ciudad de México: Instituto de Investigaciones Jurídicas, UNAM.

Freidenberg, Flavia y Raymundo Alva Huitrón. 2017. “¡Las reglas importan! Impulsando la representación política de las mujeres desde las leyes electorales en perspectiva multinivel." En La Representación Política de las Mujeres en México, editado por Flavia 
Freidenberg. Ciudad de México: Instituto Nacional Electoral e Instituto de Investigaciones Jurídicas de la Universidad Nacional Autónoma de México, 15-62.

Gelman, Andrew y Jennifer Hill. 2006. Applied Regression and Multilevel/Hierarchical Models. Cambridge: Cambridge University Press.

Gilas, Karolina M. 2014. Con las Cuotas no Basta. De las Cuotas de Género y otras Acciones Afirmativas. Ciudad de México: Tribunal Electoral del Poder Judicial de la Federación.

Gilas, Karolina M. y Mikaela Christiansson. 2018. "La paridad de género y la regla de los distritos perdedores en México." En Mujeres en la Política: Experiencias Nacionales y Subnacionales en América Latina, editado por Flavia Freidenberg, Mariana Caminotti, Betilde Muñoz-Pogossian y Tomáš Došek. Ciudad de México: Instituto Electoral de la Ciudad de México e Instituto de Investigaciones Jurídicas, de la Universidad Nacional Autónoma de México, 145-166.

Giraudy, Agustina, Eduardo Moncada y Richard Snyder. 2019. "Subnational Research in Comparative Politics Substantive, Theoretical, and Methodological Contributions." En Inside Countries: Subnational Research in Comparative Politics, editado por Agustina Giraudy, Eduardo Moncada y Richard Snyder. Cambridge: Cambridge University Press, 3-52.

González Ulloa Aguirre, Pablo Armando. 2017. “Alternancia en las Elecciones Subnacionales en México: ¿Síntoma de Democratización?” Estudios Políticos 40: 47-69.

Gujarati, Damodar N. y Dawn C. Porter. 2010. Essentials of Econometrics. Nueva York: McGraw-Hill.

Harbers, Imke y Abbey Steele. 2020. "Introduction: Subnational Variation Across States: A Typology and Research Agenda." Latin American Politics and Societies 62 (3): 1-18.

Harbers, Imke, Jos Bartman y Enrike van Wingerden. 2019. "Conceptualizing and Measuring Subnational Democracy across Indian States." Democratization 26(7): 1154-1175.

Hevia Rocha, Teresa. 2020. El Impacto de las Medidas de Acción Afirmativa de Género en el Registro de las Candidaturas en el Proceso de 2017/2018. Ciudad de México: Instituto Nacional Electoral.

Htun, Mala y Mark P. Jones. 2002. "Engendering the Right to Participate in Decision-Making: Electoral Quotas and Women's Leadership in Latin America." En Gender and the Politics of Rights and Democracy in Latin America, editado por Nikki Crake y Maxine Molineux. Basingstoke: Palgrave MacMillan, 32-56.

Inglehart, Ronald y Pippa Norris. 2003. Rising Tide. Gender Equality and Cultural Change around the World. Cambridge: Cambridge University Press.

Krook, Mona Lena. 2010. “Women's Representation in Parliament: A Qualitative Comparative Analysis." Political Studies 58(5): 886-908.

Langston, Joy y Javier Aparicio. 2014. "Why More Women Do Not Win Single-Member District Seats." Ponencia presentada en el Foro Internacional Mujeres, política, democracia. Rompiendo los Techos de Cristal en América Latina. Salamanca: Instituto de Iberoamérica, Universidad de Salamanca, 23-28 de marzo.

Jones, Mark P, Santiago Alles y Carolina Tchintian. 2012. "Cuotas de Género, Leyes Electorales y Elección de Legisladoras en América Latina." Revista de Ciencia Política 32(2): 331- 357.

Mackay, Fiona, Meryl Kenny y Louise Chappell. 2010. “New Institutionalism Through a Gender Lens: Towards a Feminist Institutionalism?" International Political Science Review 31(5): 573-588.

Massolo, Alejandra. 2007. La Participación Política de las Mujeres en el Ámbito Local en América Latina. Santo Domingo: Instituto Internacional de Investigaciones, INSTRAW.

Matland, Richard E. 1998. "Women's Representation in National Legislatures: Developed and Developing Countries." Legislative Studies Quarterly 23(1): 109-125.

México. 2014. Constitución Política de los Estados Unidos Mexicanos. México: Diario Oficial de la Federación.

México. 1990. Instituto Nacional de Estadística y Geografía, XI Censo General de Población y Vivienda. Disponible en: https://www.inegi.org.mx/programas/ccpv/1990. 
México.1995. Instituto Nacional de Estadística y Geografía, Conteo de Población y Vivienda Disponible en: https://www.inegi.org.mx/programas/ccpv/1995.

México. 2000. Instituto Nacional de Estadística y Geografía, XII Censo General de Población y Vivienda. Disponible en: https://www.inegi.org.mx/programas/ccpv/2000.

México. 2005. Instituto Nacional de Estadística y Geografía, II Conteo de Población y Vivienda. Disponible en: https://www.inegi.org.mx/programas/ccpv/2005.

México. 2010. Instituto Nacional de Estadística y Geografía, Censo de Población y Vivienda. Disponible en: https://www.inegi.org.mx/programas/ccpv/2010.

México. 2015. Instituto Nacional de Estadística y Geografía, Encuesta Intercensal. Disponible en: https://www.inegi.org.mx/programas/intercensal/2015).

México. 2020. Instituto Nacional de Estadística y Geografía, serie retropolada reducida del producto interno bruto de las entidades federativas. Disponible en: https://www. inegi.org.mx/programas/pibent/2013/.

O'Donnell, Guillermo. 1999. Counterpoints: Selected Essays on Authoritarianism and Democratization. Notre Dame: University of Notre Dame Press.

O'Neill, Thomas y Gary Hymel. 1994. All Politics Is Local: And Other Rules of the Game. New York: Times Books.

ONU Mujeres. 2018. La Participación Política de las Mujeres a Nivel Municipal en México. Ciudad de México: ONU Mujeres.

ONU Mujeres, FLACSO, PNUD y Tribunal Electoral del Poder Judicial de la Federación. 2012. Construyendo Reglas para la Igualdad de Género en Derechos Político-Electorales en México. Ciudad de México: ONU Mujeres, IDEA Internacional, PNUD y Tribunal Electoral del Poder Judicial de la Federación.

Palma Cabrera, Esperanza y Abraham Chimal. 2012. "Partidos y cuotas de género. El impacto de la ley electoral en la representación descriptiva en México." Revista Mexicana de Estudios Electorales 11 (julio): 53-78.

Peña Molina, Blanca Olivia. 2014. “Cuota de género y paridad. La protección de los derechos políticos de las mujeres en México". Ponencia presentada en el Foro Internacional Mujeres, Política y Democracia. Rompiendo los Techos de Cristal en América Latina. Salamanca: Instituto de Iberoamérica, Universidad de Salamanca, 23-28 de marzo.

Piscopo, Jennifer M. 2015. "States as Gender Equality Activists: The Evolution of Quota Laws in Latin America." Latin American Politics \& Society 57(3): 27-49.

Piscopo, Jennifer M. 2016. "When Informality Advantages Women: Quota Networks, Electoral Rules, and Candidate Selection in Mexico." Government \& Opposition 51(3): 487512.

Pitkin, Hanna. 1985. El Concepto de Representación Política. Madrid: Centro de Estudios Constitucionales.

Programa de Naciones Unidas para el Desarrollo (PNUD). 2013. ¿Cuánto hemos avanzado? Un análisis de la Participación Política de las Mujeres en los Gobiernos Subnacionales en América Latina y el Caribe. Ciudad de Panamá: PNUD.

Reynolds, Andrew. 1999. "Women in the Legislatures and Executives of the World: Knocking at the Highest Glass Ceiling." World Politics 51(4): 547-572.

Reynoso, Diego y Natalia D’Angelo. 2006. “Las Leyes de Cuota y su Impacto en la Elección de Mujeres en México." Política y gobierno 13(2): 279-313.

Rokkan, Stein. 1970. Citizens, Elections, Parties: Approaches to the Comparative Study of the Processes of Development. Nueva York: McKay.

Rosen, Jennifer. 2012. "The Effects of Political Institutions on Women's Political Representation: A Comparative Analysis of 168 Countries from 1992 to 2010." Political Research Quarterly 66(2): 1-16.

Schakel, Arjan H. 2013. "Nationalisation of Multilevel Party Systems: A Conceptual and Empirical Analysis." European Journal of Political Research 52 (12): 212-236.

Schmidt, Gregory. 2020. "Are Open or Closed Lists Better for Women?: A Comparison of Lima and the Provinces in Peru." Apuntes 86: 147-169. 
Schwindt-Bayer, Leslie A. 2018. "An Introduction to Gender and Representation in Latin America." En Gender and Representation in Latin America, editado por Leslie Schwindt-Bayer. Oxford: Oxford Scholarship, 1-16.

Snyder, Richard. 2001. "Scaling Down: The Subnational Comparative Method." Studies in Comparative International Development 36(1): 93-110.

Tello Sánchez, Flavia. 2009. La Participación Politica de las Mujeres en los Gobiernos Locales Latinoamericanos: Barreras y Desafíos para una Efectiva Democracia de Género. Tesis de Maestría, PRIGEPP/FLACSO.

Vidal Correa, Fernanda. 2016. Women in Mexican Politics: A Study of Representation in a Renewed Federal and Democratic State. Lanham, MD: Lexington Books.

Zetterberg, Pär. 2007. "Gender Quotas and Political Effectiveness Women's Experiences in Mexican State Legislatures." Presentado en el European Consortium for Political Research Joint Sessions of Workshop, Helsinki, 7-12 de Mayo.

Recibido: 4 de agosto de 2020

Aceptado: 9 de febrero de 2021

Flavia Freidenberg. Licenciada en Ciencia Política. Periodista. Maestra en Estudios Latinoamericanos y Doctora en Ciencia Política por la Universidad de Salamanca (España). Investigadora Titular " $\mathrm{C}$ " a Tiempo Completo en el Instituto de Investigaciones Jurídicas de la Universidad Nacional Autónoma de México. Miembro del Sistema Nacional de Investigadores del CONACYT (Nivel II). Coordinadora de la Red de Politólogas - \#NoSinMujeres. Sus principales áreas de investigación son la política comparada, las elecciones, los partidos políticos, las instituciones informales y la representación política de las mujeres. Investigadora de \#ObservatorioREFPOL y \#RepresentaciónParitaria. Email: flavia@unam.mx

Sebastián Garrido de Sierra Licenciado en Ciencia Política y Relaciones Internacionales (CIDE), Maestro y Doctor en Ciencia Política (UCLA), Profesor Asociado en el CIDE. Su investigación abarca temas relacionados con política mexicana, equidad de género, educación superior, transparencia y la intersección entre estos temas. Investigador de \#ObservatorioREFPOL y \#RepresentaciónParitaria. Email: sebastian.garrido@cide.edu. 


\section{ANEXO}

Tabla A. Resumen estadístico de las variables de respuesta y explicativas

\begin{tabular}{|c|c|c|c|c|c|c|}
\hline Variable & $\begin{array}{l}\text { Rango de } \\
\text { valores }\end{array}$ & $\begin{array}{l}\text { Media } \\
\text { general }\end{array}$ & $\begin{array}{l}\text { Rango de } \\
\text { medias } \\
\text { estatales }\end{array}$ & $\begin{array}{l}\text { Desviación } \\
\text { estándar } \\
\text { general }\end{array}$ & $\begin{array}{l}\text { Rango de } \\
\text { des. estándar } \\
\text { estatales }\end{array}$ & $\begin{array}{l}\text { Valores } \\
\text { faltantes }\end{array}$ \\
\hline \multicolumn{7}{|l|}{ Proporción } \\
\hline legisladoras & $0-0.61$ & 0.221 & $0.144-0.354$ & 0.157 & $0.093-0.218$ & 0 \\
\hline \multicolumn{7}{|l|}{ MR } \\
\hline $\begin{array}{l}\text { Proporción } \\
\text { legisladoras RP }\end{array}$ & $0-1$ & 0.284 & $0.169-0.438$ & 0.173 & $0.075-0.325$ & 0 \\
\hline IFREG MR & $0-5$ & 1.170 & $0.091-2.14$ & 1.475 & $0.189-2.11$ & 0 \\
\hline IFREG RP & $0-5$ & 1.695 & $0.4-3.31$ & 1.913 & $0.843-2.46$ & 0 \\
\hline $\begin{array}{l}\text { Antigüedad } \\
\text { norma de } \\
\text { género }\end{array}$ & $1-24$ & 9.27 & $3-13.5$ & 5.729 & $1.41-7.35$ & 100 \\
\hline $\begin{array}{l}\text { PIB per cápita } \\
\text { estatal } \\
\text { (Pesos } \\
\text { constantes de } \\
\text { 2013) }\end{array}$ & $\begin{array}{c}49,759- \\
1,405,058\end{array}$ & 148,437 & $\begin{array}{c}56,641- \\
1,025,222\end{array}$ & 164,597 & $2,532-314,551$ & 0 \\
\hline $\begin{array}{l}\text { Urbanización } \\
(\%)\end{array}$ & $\begin{array}{c}44.14 \mathrm{a} \\
99.76\end{array}$ & 74.52 & $47.3-99.6$ & 14.59 & $0.11-5.83$ & 0 \\
\hline $\begin{array}{l}\text { Educación } \\
\text { superior (\%) }\end{array}$ & $5.8-32.1$ & 14.96 & $9.04-26.5$ & 4.62 & $2.01-4.73$ & 52 \\
\hline Alternancia & 0 ó 1 & 0.484 & $0-1$ & 0.5 & $0-0.535$ & 0 \\
\hline
\end{tabular}

Fuente: Elaboración propia. 
